\title{
BASIC OPTOKINETIC-OCULAR REFLEX PATHWAYS IN THE FROG $^{1}$
}

\author{
S. L. COCHRAN, ${ }^{2}$ N. DIERINGER, AND W. PRECHT \\ Brain Research Institute, University of Zürich, Zürich, Switzerland
}

Received August 3, 1982; Revised June 28, 1983; Accepted June 29, 1983

\begin{abstract}
Frogs (Rana temporaria) have two midbrain nuclei that receive contralateral retinal afferents, and whose neurons respond to optokinetic stimulation. The basal optic nucleus is composed of direction-selective neurons with different response types. One type is activated exclusively by upward moving optokinetic targets; another type is activated only by downward moving targets. Two other types of basal optic neurons show this vertical preference, but each is also activated by patterns moved horizontally from the nasal to temporal visual field. No activation of these cells was found with patterns moved horizontally from the temporal to nasal visual fields. Rather, cells in a discrete pretectal region have this type of sensitivity: they increase their resting rate with temporal to nasal stimulation and decrease it with nasotemporal stimulation.

Oculomotor neurons (antidromically identified) have similar optokinetic sensitivities. As with basal optic neurons, these cells have exclusively upward or downward sensitivity, and some also have nasotemporal sensitivity. An additional type of oculomotor neuron and abducens motoneurons are activated by temporonasal pattern movement. In general, the extraocular motoneurons have similar velocity and pattern size preferences, as have the sensory nuclei.

Investigations of the connectivity between the sensory and motor nuclei were primarily restricted to the relation between the pretectum and the abducens. A monosynaptic connection between the pretectum and the abducens is suggested by four points: (1) excitatory postsynaptic potential onset latency in antidromically identified abducens motoneurons, following optic nerve stimulation, is consistent with the interpretation of a disynaptic pathway to the abducens from the retina; (2) pretectal cells, sensitive to optokinetic stimulation, can be activated antidromically from stimulation of the abducens nucleus; (3) horseradish peroxidase injections into the pretectum result in labeling of axons, which terminate in the abducens nucleus; (4) horseradish peroxidase injections into the abducens result in labeling of cells in the pretectal region, where optokinetically sensitive cells are found.

In the frog, there seem to be three-neuronal retino-ocular reflexes mediating optokinetic slow phase behavior as there are three-neuronal vestibulo-ocular reflexes that also mediate compensatory spatial behavior. It is suggested that these direct connections act to initiate ocular movements and accelerate the eye, whereas more indirect pathways may act to maintain eye position.
\end{abstract}

The optokinetic reflex is common to all animals studied and has been extensively investigated in mammals. The vast complexity of the mammalian brain hinders a concise understanding of the means by which the central nervous system mediates this behavior. Although certain

\footnotetext{
${ }^{1}$ This study was supported by the Max Planck Society, the Swiss National Science Foundation (Grants 3.505.79 and 3.616.80), and the Eric Slack-Gyr Foundation. We thank Margrit Cavegn, Elisabeth Hitz, Johann A. Künzli, and Eva Schneider for their technical assistance.

${ }^{2}$ To whom correspondence should be addressed, at Brain Research Institute, University of Zürich, August Forel-Str. 1, CH-8029 Zürich, Switzerland.
}

pathways and systems are known to be involved in the transmission of optokinetic signals, the relative contribution of these neuronal pathways to the behavior is unclear (cf. Precht, 1982). In an attempt to minimize this overwhelming complexity and to understand how other vertebrate nervous systems may manipulate these optokinetic signals, we have investigated the optokinetic system of the frog, which has a smaller and perhaps a more simply organized brain and a well described optokinetic behavior (Birukow, 1937; Dieringer and Precht, 1982; Dieringer et al., 1982a, b).

Previous investigations of the frog optokinetic system have indicated that midbrain regions are significant in 
receiving optokinetic information from the retina (Lázár, 1973). Other studies have reported the existence of cells in this general area that have optokinetic sensitivity to patterns moved either vertically or horizontally, or in both directions (Kondrashev and Orlov, 1976; Gruberg and Grasse, 1980; Katte and Hoffman, 1980; Skarf and Melvill-Jones, 1981; Williams et al., 1981). In this study, we have attempted to define more clearly the specific brain regions which contribute to the frog's optokinetic responsiveness, and to establish the most direct route by which optokinetic stimuli may effect a motor response of the eye. A portion of these investigations has been published previously in abstract form (Cochran and Precht, 1980; Cochran et al., 1980, 1981a, b).

\section{Materials and Methods}

Experiments were performed over a period of 2 years on approximately 400 frogs (Rana temporaria). All surgical procedures were conducted with the animal maintained under general anesthesia. The frogs were first immersed in a $0.2 \%$ solution of MS222 (3-aminobenzoic acid ethyl ester) and, at the cessation of reflexive activity, were then placed in ice, which acted to prolong anesthesia and reduce bleeding. Subsequent electrophysiology was performed at room temperature $\left(19\right.$ to $\left.24^{\circ} \mathrm{C}\right)$.

Electrophysiological experiments. These experiments involved electrical stimulation of cranial nerves (II, VI, III/IV) and various brain regions while recording from midbrain and medullary nuclei (see below). Electrical stimulation of cranial nerves was accomplished by applying single square wave current pulses $(0.1$ to $3 \mathrm{~mA}, 100$ $\mu \mathrm{sec}$ ) to a $30-\mu \mathrm{m}$-diameter wire (insulated except for approximately $0.5 \mathrm{~mm}$ at the tip), which was hooked around the appropriate cranial nerve. In most cases (see "Results"), the optic nerve-stimulating electrodes were located intracranially (leaving the nerve intact), whereas abducens and oculomotor nerve electrodes were placed intraorbitally. These electrodes were fixed to the animal by means of cyanoacrylate glue, which also reinforced the insulation. Extreme care was taken when implanting the optic nerve-stimulating electrode, as stretching or squeezing prevented transmission of visual responses to the brain. Brain regions were stimulated with monopolar or bipolar etched, insulated insect pin(s).

Extra- and intraccllular rccording employed the use of beveled (Brown and Flaming, 1974), glass microelectrodes filled with $3 \mathrm{M}$ potassium citrate or potassium methylsulfate. In some cases, electrodes were filled with $4 \%$ horseradish peroxidase (HRP) in $0.2 \mathrm{M} \mathrm{KCl}$, buffered to $\mathrm{pH} 8.6$ with $50 \mathrm{~mm}$ 'I'ris. Recording sites could then be localized histologically after passing anodal current through these electrodes (10 to 30 megohms, 0.1 to $1 \mu \mathrm{A}$, 5 to $30 \mathrm{~min}$; cf. Snow et al., 1976). Following placement of the stimulating electrodes ventrally, the dorsal surface of the cranium was opened with the aid of a dental drill. Recording from and stimulation of the abducens nucleus also necessitated the exposure of the medulla and careful removal of the choroid plexus overlying the fourth ventricle. Animals were then placed upon a platform to which was attached a piece of cork and were covered with moist gauze. The angle of the head was fixed approximately $10^{\circ}$ above the horizontal. One eye was com- pletely covered with a piece of moistened skin, thereby blocking its vision. The animal was then immobilized by an intralymphatic injection of Alloferine ( $d$-tubocurarine chloride; $\sim 0.025 \mathrm{mg}$ ). General anesthesia was then allowed to terminate, usually taking about $1 \mathrm{hr}$.

No local anesthesia was used, as such agents tended to diffuse into the exposed brain regions and circulatory system and thus blocked neural and cardiovascular activity. Therefore, during the course of the surgical procedure, all cutaneous nerves proximal to the region of the incisions were cauterized to minimize any painful sensation following termination of anesthesia. These nerves included particularly those dorsally of the back and around the eyes and those ventrally of the mouth and nose. Recording sessions were also limited to approximately $5 \mathrm{hr}$ or until the animal's viability seemed grossly diminished. Those animals not to be investigated histologically were killed by rapid and extensive maceration of the brain, followed by severing of the major arteries. Animals processed for histology were immersed in $0.2 \%$ MS222 in Ringer solution for $1 / 2 \mathrm{hr}$ ( $15 \mathrm{~min}$ being normally long enough to observe anesthesia in an unparalyzed animal) and then cooled in ice prior to perfusion.

It was necessary during these unitary recordings to measure the responsiveness of individual cells to optokinetic pattern movement. To achieve this stimulus, a random dot or, more often, a striped pattern on an index card was placed approximately $5 \mathrm{~cm}$ from the animal's one seeing eye. This pattern was mounted onto a bar connected to a potentiometer so that the bar and pattern could be rotated by hand in either the horizontal or vertical planes. The output of the potentiometer provided a position signal which could be recorded concomitantly with the unitary responses over time. Quantitative measurements were only approximate since the hand-driven movements were somewhat irregular at the slow, optimal pattern velocities. Only the portions where the pattern moved at constant velocity were utilized in cases where a cell's responsiveness was plotted versus stimulus velocities.

Anatomical investigations. In many instances, after electrophysiological recording, anesthesized frogs were perfused with Ringer followed by a fixative containing $4 \%$ glutaraldehyde and $1 \%$ paraformaldehyde. Brains werc subsequently removed and processed histologically, and sections were stained histochemically with diaminobenzidine (Graham and Karnovsky, 1966). These investigations employed electrophoretic injections into nuclei--e.g., oculomotor, abducens, and pretectal. Electrodes were filled with 5 to $10 \% \mathrm{HRP}$ in $0.2 \mathrm{M} \mathrm{KCl}$, buffered to $\mathrm{pH} 8.6$ with $50 \mathrm{~mm}$ Tris, and were broken to a resistance of less than 10 megohms. Initially, extraocular motor nuclei were localized by antidromic field potentials, but this was subsequently found not to be necessary. These motor nuclei injections were found to be more accurately placed and less disruptive to the animal when performed through the ventral surface of the brain, where the exits of motor nerves could be easily visualized. Pretectal injections were performed by injecting the rostral tectum approximately $1 \mathrm{~mm}$ ventral to the dorsal tectal surface, where cells sensitive to optokinetic stimulation are found. Injection currents ranged from 0.1 to 
$5 \mu \mathrm{A}$ (anodal) for periods of from 5 to $20 \mathrm{~min}$. Histological processing and histochemical staining were performed as above, and section thickness ranged from 30 to $100 \mu \mathrm{m}$. Survival times ranged from 2 to 10 days, 5 to 6 days being optimal in most cases. Only homogeneously labeled perikarya, dendrites, and axons were considered labeled, as many neurons in the frog brain appear to contain endogenous, granular peroxidase. The size of the injection site was estimated by including within it all regions of the brain in which apparent extracellular reaction product could be found, and by then determining the mean diameter. Such estimates were only approximate, as the long survival times used precluded a clear definition of the borders of the injection site. From our attempts, diaminobenzidine was found to be more effective than either tetramethylbenzidine or Hanker-Yates reagents in exposing clearly these peroxidase-labeled cells and their parts.

\section{Results}

Extraocular motoneurons. As in other vertebrates, oculomotor and trochlear motoneurons in the frog innervate five extraocular muscles (Gaupp, 1896; Matesz and Székely, 1977). These motoneurons show different responses to optokinetic stimulation of the eye which they control. Table I summarizes a survey of the directional preferences of 37 antidromically identified oculomotor and trochlear motoneurons. Directional preferences could be divided into basically five types: (1) those which were activated by upward moving stimuli only; (2) those activated by downward moving stimuli only; (3) those activated by upward and nasotemporally moved stimuli (Fig. 1, $A$ and $B$ ); (4) those activated by downward and nasotemporally moved stimuli; and (5) those activated by temporonasally moved stimuli (Fig. $1 C$ ). In the last category, two cells were tested for vertical pattern movement and were found to be weakly activated by upward movement. In nearly every instance, when a cell exhibited a resting firing rate, this spontaneous activity could be silenced by pattern movement $180^{\circ}$ opposite to the activation direction (Fig. $1, A$ and $B$ ). From a qualitative aspect, it seemed that the vertically sensitive cells responded to much slower velocities and required larger receptive fields than did the temporonasally activated motoneurons (and abducens; see below). Some antidrom-

TABLE I

Directional preferences of oculomotor (III) and basal optic neurons $(B O N s)^{a}$

\begin{tabular}{|c|c|c|c|c|c|c|c|}
\hline \multirow[b]{2}{*}{ Nucleus } & \multicolumn{7}{|c|}{ Direction } \\
\hline & $\begin{array}{l}\text { Down } \\
\text { only }\end{array}$ & $\begin{array}{l}\text { Down } \\
\text { N-T }^{b}\end{array}$ & $\begin{array}{c}\text { Down } \\
?^{c}\end{array}$ & $\begin{array}{l}\text { Up } \\
\text { only }\end{array}$ & $\begin{array}{c}\mathrm{Up} \\
\mathrm{N}-\mathrm{T}\end{array}$ & $\begin{array}{c}\text { Up } \\
?\end{array}$ & $\mathrm{~T}-\mathrm{N}^{d}$ \\
\hline III & $5^{e}$ & 4 & & 4 & 5 & & 19 \\
\hline BON & 7 & 13 & 1 & 7 & 4 & 7 & 0 \\
\hline
\end{tabular}

"Patterns were presented to the eye ipsilateral to the oculomotor and contralateral to the basal optic nucleus.

${ }^{b} \mathrm{~N}-\mathrm{T}$, nasotemporal.

? , horizontal directions not tested.

${ }^{d} \mathrm{~T}-\mathrm{N}$, temporonasal.

e Numerical values represent the number of cells activated by a specified direction. ically activated cells (less than $10 \%$ ) were unresponsive to optokinetic stimulation.

Directly beneath the floor at the fourth ventricle, between the entrances of cranial nerves VIII and IX, sit two closely associated clusters of neurons that comprise the abducens nucleus. The abducens proper motoneurons innervate the lateral rectus muscle and are situated quite medially, while more laterally are located the accessory abducens motoneurons that innervate the retractor bulbi muscles (Gaupp, 1896; Matesz and Székely, 1977). These two populations can be distinguished electrophysiologically by their response properties. Abducens proper motoneurons have a low firing rate (approximately $5 \mathrm{im}$ pulses/sec) and are sensitive to horizontal optokinetic stimulation. Accessory abducens motoneurons are typically spontaneously inactive, are insensitive to optokinetic stimulation, and fire in short bursts when active, as expected of motoneurons responsible for eye "blinks." As the eye "blinks," these bursts can be elicited by touching the cornea of either eye. Twenty-six antidromically identified abducens motoneurons were activated by temporonasal pattern movement presented to the contralateral eye (Fig. 1D). Nasotemporal movement silenced these cells. In one animal, the ipsilateral eye was visually stimulated and the motoneurons increased their firing activity with nasotemporal pattern movement and decreased it with temporonasal pattern movement (the contralateral eye was enucleated).

These extraocular motoneurons were also orthodromically activated by intracranial stimulation of the optic nerve. Excitatory postsynaptic potentials (EPSPs) found in 14 oculomotor neurons (ipsilateral optic nerve stimulation) had a mean latency of $5.2 \pm 0.2 \mathrm{msec}$ (SEM; Fig. $2 A$ ). EPSPs in 16 abducens motoneurons (contralateral optic nerve stimulation) had a mean latency of $6.1 \pm 0.4$ msec (SEM; Fig. 2B). An example of such an abducens motoneuron is shown in Figure 3. To minimize current spread, in three experiments the optic disc was stimulated instead of the optic nerve. EPSPs in abducens motoneurons had a latency similar to those from intracranial stimulation of the optic nerve (approximately 6 $\mathrm{msec}$ ). It was not possible to determine in the majority of these cells their optokinetic sensitivity prior to impalement.

The basal oplic nucleus. The basal optic nucleus is characterized as a terminal neuropil of retinal afferents which are anatomically segregated from the major retinotectal projection and which terminate just rostromedial to the exit of the oculomotor nerve at the ventral surface of the brain (Scalia, 1976; Montgomery et al., 1981; Fig. 4). Thus, with a microelectrode approach ventrally through the mouth, one can easily localize this region (see, for instance, Kondrashev and Orlov, 1976), particularly if stimulating the contralateral optic nerve. Close to the optic chiasm and somewhat medial, a sharp triphasic potential can be detected within the first few hundred micrometers from the ventral midbrain surface. More caudally, this sharp triphasic wave (onset of peak negativity: $1.5 \pm 0.2 \mathrm{msec}$ (SEM; $n=4)$ ) is followed by a slower negativity (onset latency: $2.7 \pm 0.2 \mathrm{msec}$ (SEM; $n=4)$ ) (Fig. 5). More laterally, medially, or caudally there is no response. The triphasic wave most likely 

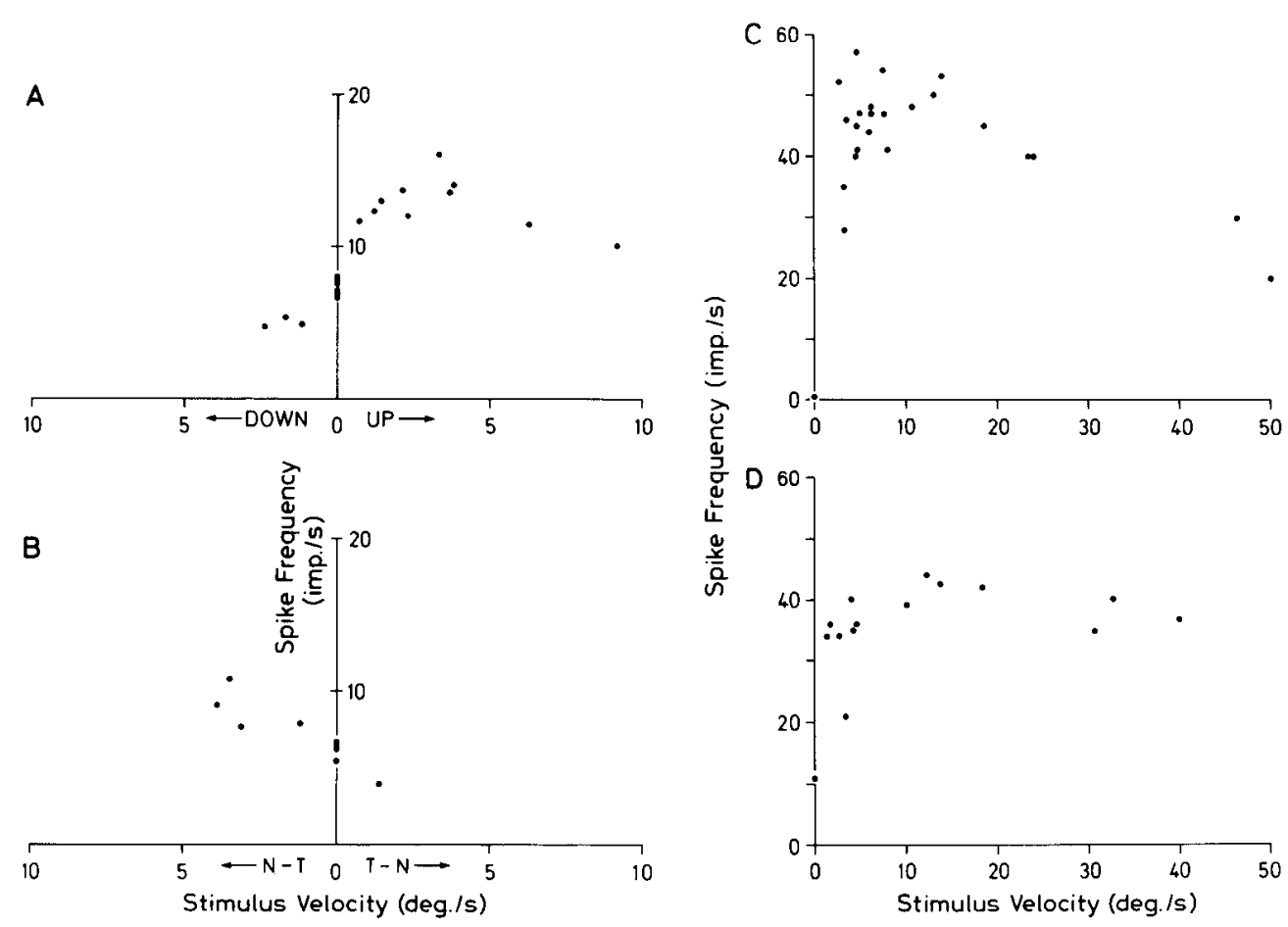

Figure 1. Response characteristics of antidromically identified extraocular motoneurons to optokinetic stimulation. $A$ and $B$, Sensitivity of an oculomotor neuron (ipsilateral to the stimulated eye) to vertical $(A)$ and horizontal $(B)$ optokinetic stimulation. $C$, Sensitivity of an oculomotor neuron (ipsilateral to the seeing eye) to temporonasally directed movement. 'I'his cell did not respond to nasotemporal pattern movement. $D$, Sensitivity of an abducens motoneuron (contralateral to the stimulated eye) to temporonasally directed pattern movement. Each point represents an individual measurement during constant velocity stimulation. $N-T$, nasotemporally or posteriorly directed movement; $T-N$, temporonasally or anteriorly directed movement.

represents the compound action potential of presynaptic retinal afferents of the basal optic root, while the slower negativity is probably related to synaptic depolarization of the dendrites within the basal optic neuropil. Detection of this field potential is difficult when lowering the microelectrode from the dorsal tectal surface, because the neuropil is small and is located approximately $2 \mathrm{~mm}$ ventral. However, identification of this field as being generated in the basal optic nucleus is unambiguous, as the pathway to the basal optic nucleus is so discrete, and HRP ejection from the recording microelectrode or localization of electrode tracks verifies that the site of this field is coincident with the basal optic nucleus (Figs. 6, $A$ and $B$, and 7). Labeled axons could be traced rostrally within the basal optic root, where they decussated and joined the contralateral optic nerve, indicating that the injected region was within the terminal field of the basal optic root. Ispilateral optic nerve stimulation results in little or no response of this neuropil (Fig. 5), reflecting the paucity of ipsilateral retinal afferents (Scalia, 1976; Montgomery et al., 1981).

Unitary spike potentials evoked by contralateral optic nerve stimulation can be detected within this region (Fig. $8, A 1$ and $A 2$ ), and intracellular recordings reveal the presence of slowly rising EPSPs that give rise to these action potentials (Fig. 8, B1 and B2). HRP ejection from the recording microelectrode following such intracellular recording occasionally labeled only very few cells within the hasal optic region as shown in Figure 9. The mean

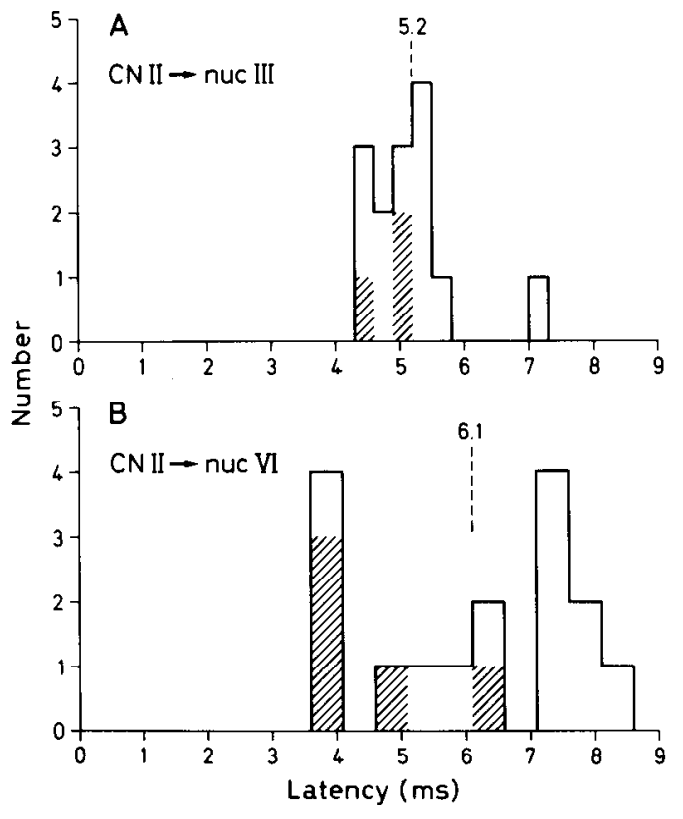

Figure 2. Histograms of EPSP latencies in extraocular motoneurons. $A$, Oculomotor neuron latencies to ipsilateral optic nerve stimulation. $B$, Abducens motoneuron EPSP latencies to contralateral optic nerve stimulation. Means of latencies are indicated above each histogram. Hatched areas indicate cells sensitive to optokinetic stimulation. Open areas represent cells either not tested for (the majority) or unresponsive to such stimulation. 

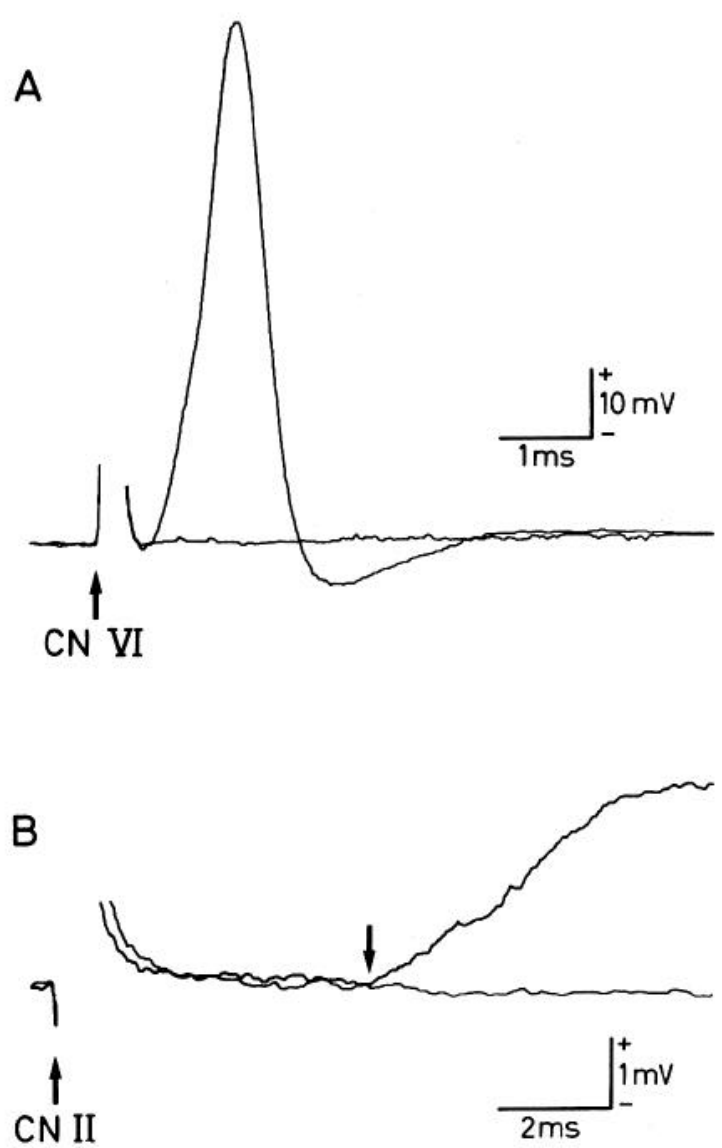

Figure 3. Intracellular recordings from an abducens motoneuron. $A$, Antidromic activation at threshold from intraorbital stimulation (arrow) of the abducens nerve $(C N V I)$. B, Orthodromic activation of the cell shown in $A$ from contralateral optic nerve stimulation (CN II, arrow). The extracellular field is superimposed upon the intracellular response (average of 8 responses each). The downward deflected arrow denotes onset of EPSP.

EPSP onset latency of such cells was $3.3 \pm 0.1 \mathrm{msec}$ (SEM; $n=32$ ), and the mean spike onset latency was $5.4 \pm 0.2 \mathrm{msec}$ (SEM; $n=64$ ) (Fig. 10).

The cells of this region are also sensitive to optokinetic stimulation. Although not investigated to any quantitative extent, it was clear that these cells required very large targets and very slow stimulus velocities for optimal activation. All of the 26 cells investigated were activated by electrical stimulation of the contralateral optic nerve, and nearly all had such low firing rates in the absence of pattern movement that it was impossible to determine the preferred null directions. These neurons could be grouped into four different types of directional preference (Table I): (1) those activated by exclusively upward pattern movement; (2) those activated by exclusively downward pattern movement; (3) those activated by upward and by nasotemporally directed pattern movement; and (4) those activated by downward and by nasotemporally directed pattern movement. None of these cells were activated by temporonasally directed pattern movement presented to the contralateral eye. One cell possessed a firing rate at rest, and we were able to quantify in a limited fashion its stimulus preferences. Its response pattern to the four directions of movement are depicted in Figure 11. The location of those and other units was within the basal optic neuropil (Figs. 6, $C$ to $F, 7$, and 9). Such anatomical localization was successful in 10 frogs from which 45 cells were recorded.

The pretectal nucleus. Unlike the basal optic nucleus,

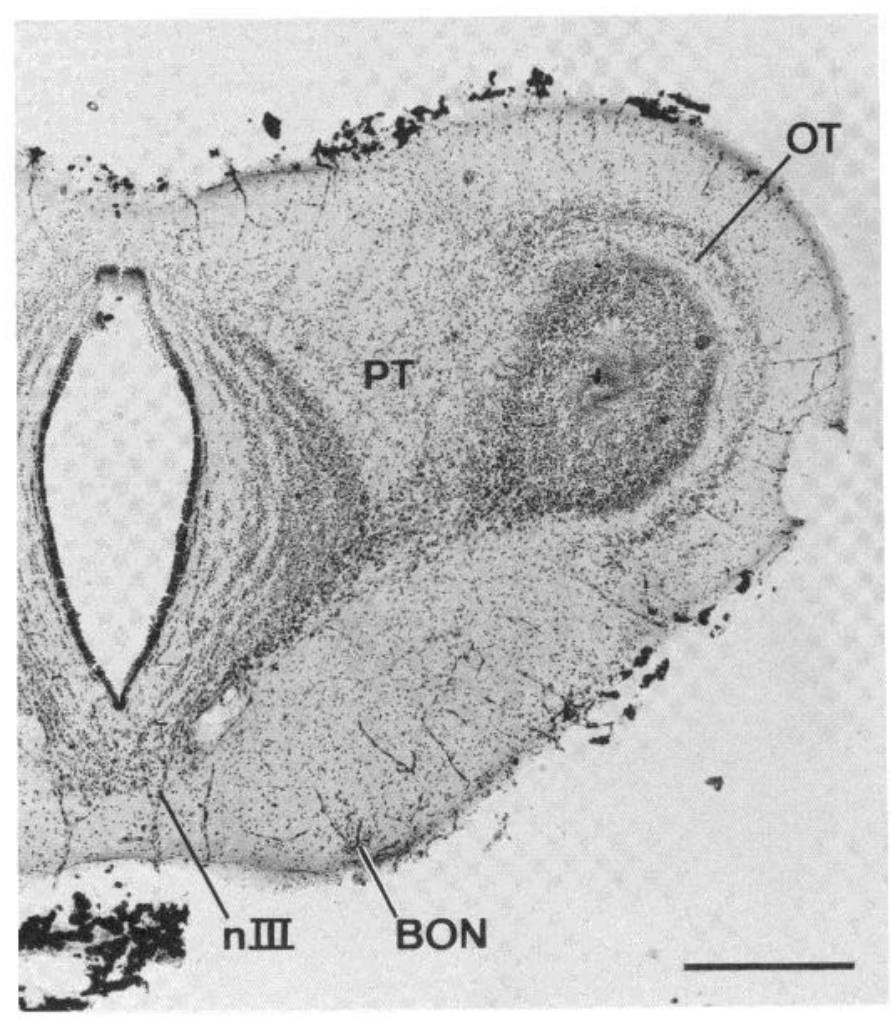

Figure 4. Nissl-stained coronal section ( $35 \mu \mathrm{m})$ through frog midbrain at the level of the diencephalomesencephalic junction. The poorly differentiated regions of pretectum $(P T)$ and basal optic neuropil $(B O N)$ as well as the oculomotor nucleus $(n I I I)$ and optic tectum $(O T)$ are indicated. Calibration bar, $0.5 \mathrm{~mm}$.

A

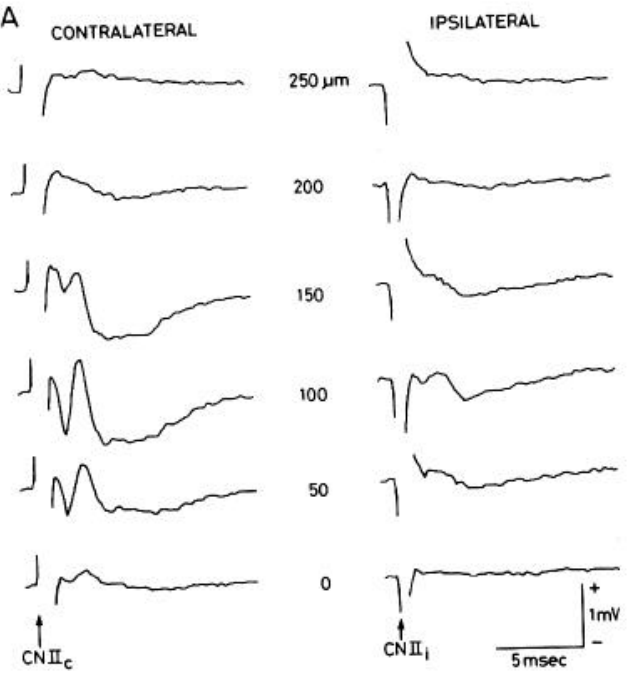

Figure 5. Characteristic field potential profiles through the basal optic neuropil evoked by stimulation of the contralateral $(C N I I \hat{c})$ and ipsilateral $(C N I I \hat{\imath})$ optic nerves. Note differences in response magnitudes. Each trace is the average of 16 stimuli. Depths are measured from the ventral midbrain surface. 
there was no clear, discrete field potential that provided an electrophysiological landmark for the pretectal cells. Therefore, three criteria were established in localizing these neurons: (1) they responded in a direction-selective fashion to horizontal optokinetic stimuli; (2) they were located between 800 and $1200 \mu \mathrm{m}$ in depth from the rostral tectal surface; and (3) they were activated at a short latency from electrical stimulation of the contralateral optic nerve. Even with these criteria, it was extremely difficult to detect these cells. Indeed, in 30 of 59 frogs, this nucleus could not be located. This difficulty may be attributed to extreme sensitivity of these appar-
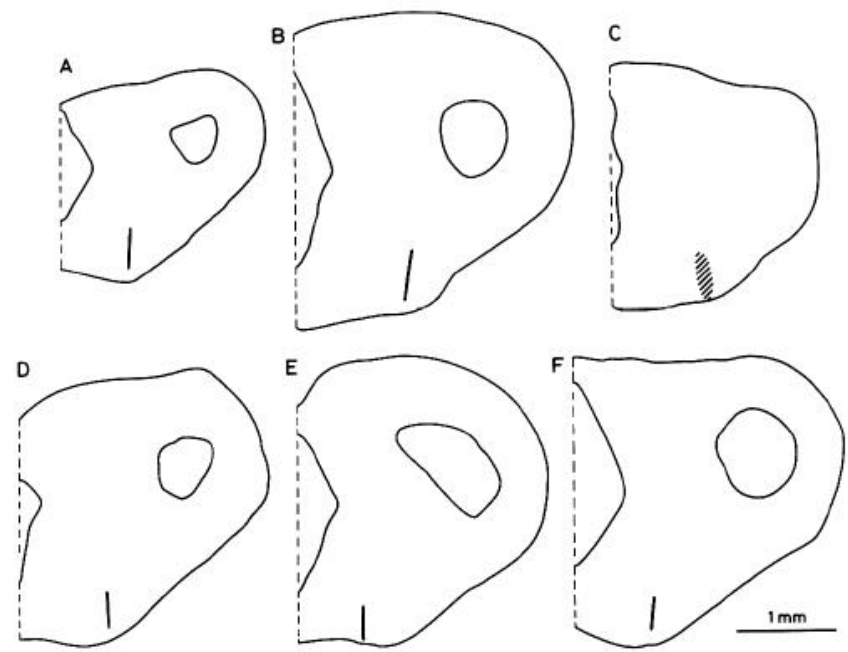

Figure 6. Histological verification of basal optic recording sites from six different animals. $A$ and $B$, Lines indicate the location of electrode tracks following field potential recordings as in Figure 5. C, Localization following extracellular field and unitary spike potential recording. The hatched area indicates the extent of spread of reaction product. $D$ to $F$, Lines indicate electrode tracks in each brain, recovered following unitary recordings as in Figure 8. Cells were found along the track in $F$, sensitive to vertical optokinetic stimulation. Each drawing represents a $35-\mu \mathrm{m}$ coronal section at the level of the electrode tracks or injections. ently small cells to repeated electrode penetrations, to the apparent small size of this nucleus itself, and perhaps to individual variations in the location of this nucleus.

Sixty-one cells were activated by temporonasally directed optokinetic stimulation of the contralateral eye. All of these cells were spontaneously active with firing rates of approximately 2 to 10 impulses/sec. Nasotemporally directed stimuli presented to the contralateral eye silenced these cells. Plots of the response characteristics of six of these cells to various stimulus velocities in the temporonasal direction are depicted in Figure 12. It was also found that movement of the experimenter's hand at a distance of approximately $1 \mathrm{~m}$ could activate or silence these cells in a direction-selective manner. Six cells were also qualitatively tested for vertically directed pattern movement sensitivity. Four were weakly activated by downward movement, one was weakly activated by upward movement, and one was insensitive to vertical movement. Seven other cells, also activated at a short latency from contralateral optic nerve stimulation, were
A

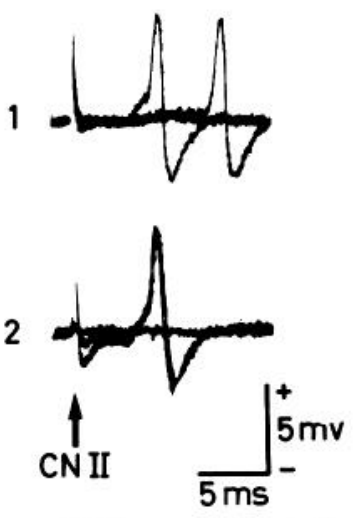

B

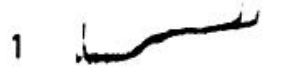

2
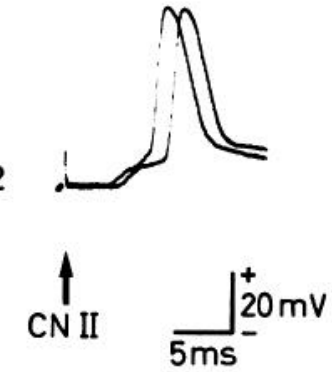

Figure 8. Extracellular $(A)$ and intracellular $(B)$ recordings from basal optic neurons activated by contralateral optic nerve stimulation ( $C N I I$, arrows). Intensity of stimulation is increased from 1 to 2 in both $A$ and $B$.
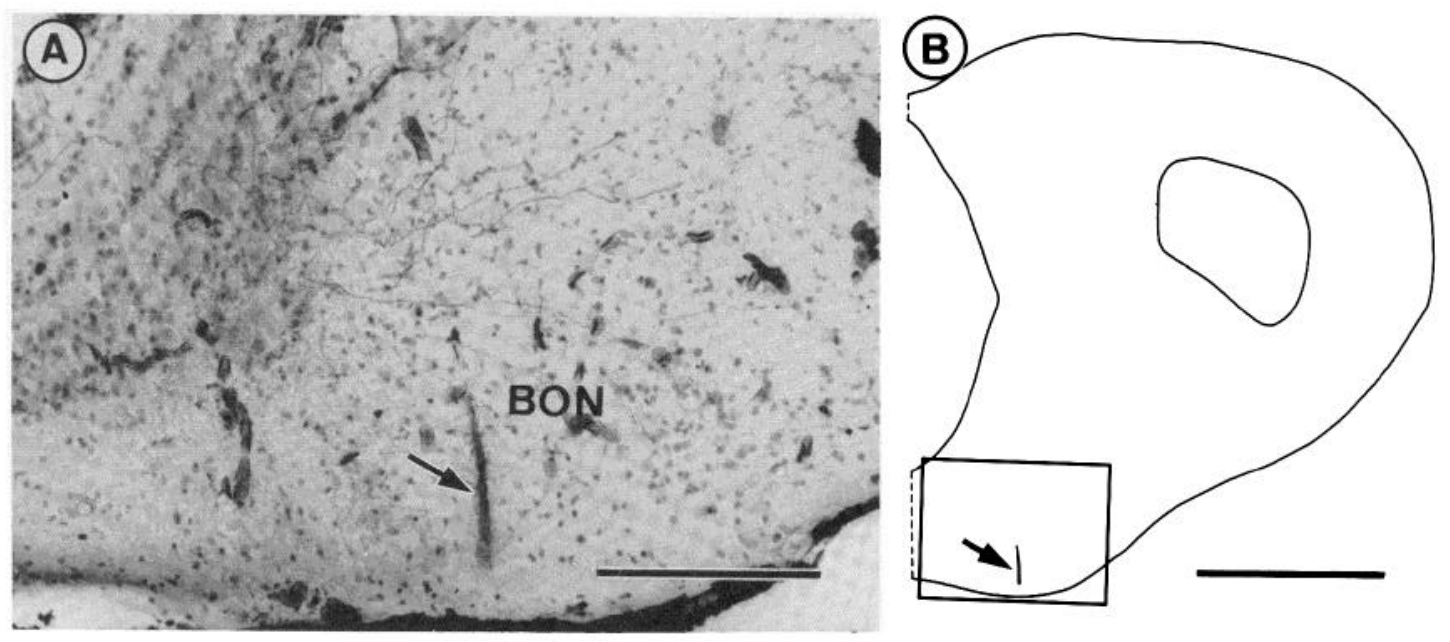

Figure 7. Histological section ( $35 \mu \mathrm{m}$, coronal) through the HRP injection site after field potential recordings as in Figure 5. $A$, Photomicrograph of the ventral midbrain region outlined in the drawing of the section $(B)$. The arrow depicts the central track of the HRP injection. $B O N$, central region of the basal optic neuropil. Calibration bars: $A, 0.25 \mathrm{~mm} ; B, 1 \mathrm{~mm}$. 


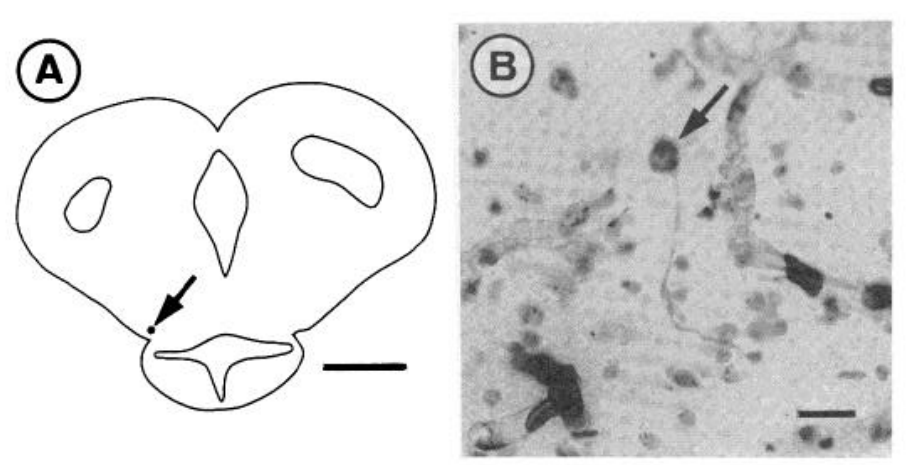

Figure 9. Histological characterization of basal optic recording site. $A$, Drawing of coronal section through the basal optic region. $B$, Photomicrograph of delineated point (arrow) in $A$. The arrow points to a single labeled basal optic neuron following cell characterization as in Figure 8 and subsequent HRP injection. Cells, which responded to vertical optokinetic stimulation, were also found in the same electrode track (and depth). A few fibers were also found to be labeled in adjacent sections. Calibration bars: $A, 1 \mathrm{~mm} ; B, 25 \mu \mathrm{m}$.
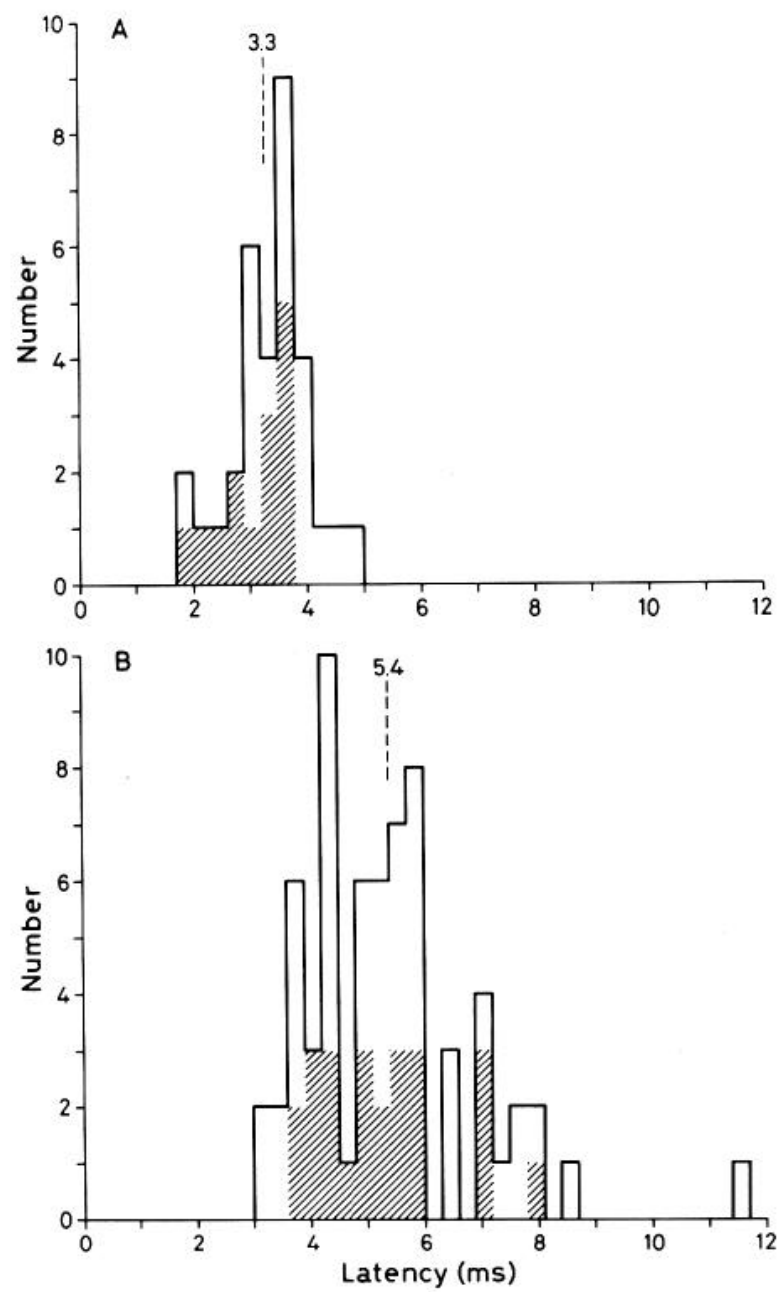

Figure 10. Histograms of latencies of basal optic neurons to contralateral optic nerve stimulation. $A$, Intracellularly recorded EPSP onset latencies; $B$, extracellularly recorded spike onset latencies. Hatching indicates cells that responded to vertical optokinetic stimulation. Open areas denote cells not tested for optokinetic sensitivity (the majority) or those unresponsive. Mean values are indicated above each histogram for intracellular (3.3) and extracellular (5.4) latencies.

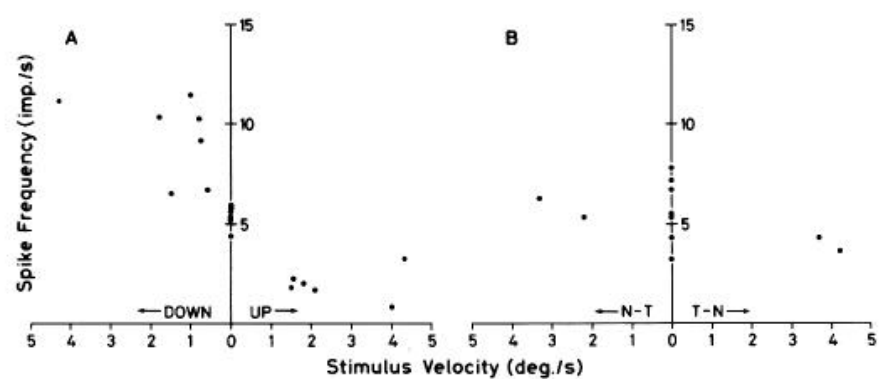

Figure 11. Optokinetic sensitivity of a spontaneously active basal optic neuron to vertical $(A)$ and horizontal $(B)$ pattern movement presented to the contralateral eye. $N-T$ indicates nasotemporal and $T-N$ indicates temporonasal pattern movement. Each point represents an individual measurement at constant velocity stimulation.

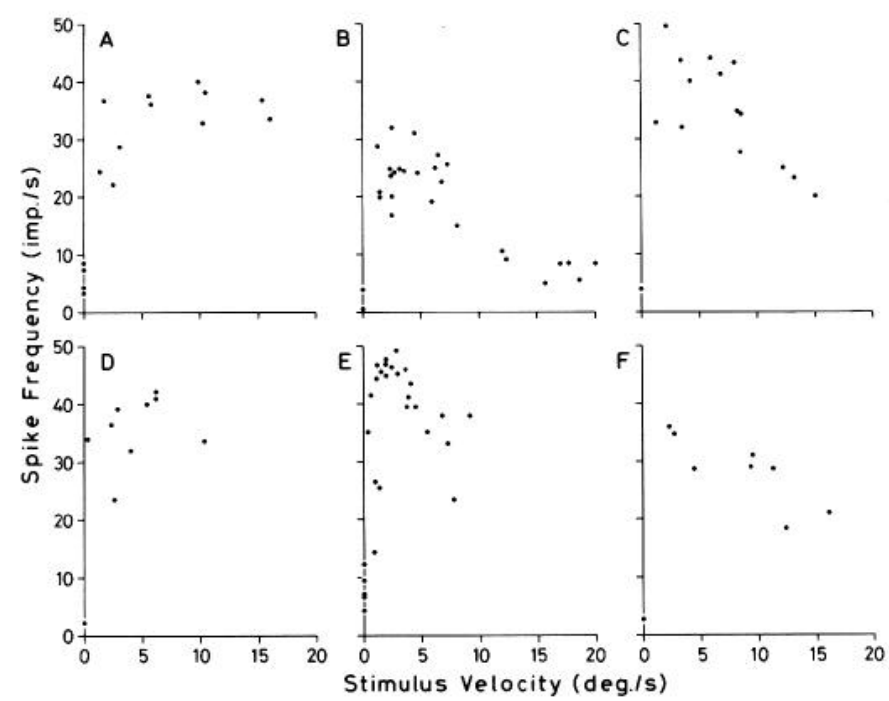

Figure 12. Optokinetic sensitivity of six different pretectal neurons to temporonasally directed pattern movement presented to the contralateral eye. All cells were silenced by nasotemporally directed pattern movement. Each point represents an individual measurement at constant velocity stimulation.
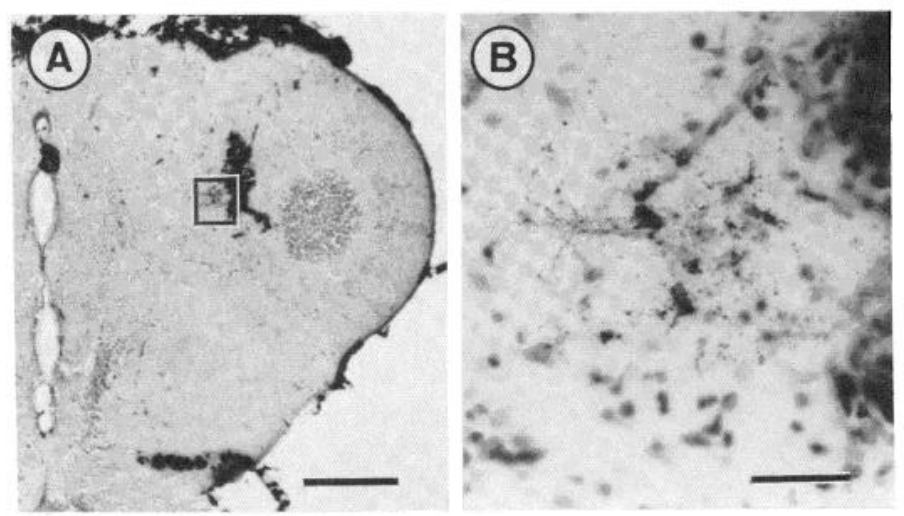

Figure 13. Pretectal recording site. $A$, Photomicrograph of a coronal section $(35 \mu \mathrm{m})$ of midbrain after injection of HRP from the recording microelectrode. The dark deposit is blood, and a small deposit of HRP can be seen adjacent to this area (boxed area, enlarged in $B$ ). Cells were found in this region that were sensitive to horizontal optokinetic stimulation and that activated at a short latency from contralateral optic nerve stimulation. Calibration bars: $A, 0.5 \mathrm{~mm} ; B, 50 \mu \mathrm{m}$. 
activated by nasotemporally directed pattern movement and silenced by temporonasally directed movement. In 10 frogs, where 39 units were found, HRP injection sites and/or electrode tracks could be successfully located (Fig. 13). All sites were found between 800 and $1200 \mu \mathrm{m}$ ventral to the rostral tectal surface (for examples, see Fig. 14) in a relatively undifferentiated portion of dorsal midbrain (see Fig. 4).

Electrical stimulation of the contralateral optic nerve evoked action potentials in these cells at a mean latency of $4.3 \pm 0.2 \mathrm{msec}$ (SEM; $n=23$; latency to spike peak; Fig. 15). Intracellular recordings from these neurons were rare. However, one such case is illustrated in Figure 16. Optic nerve stimulation evoked graded EPSPs in this cell at a relatively fixed latency (Fig. 16A). Stimulation
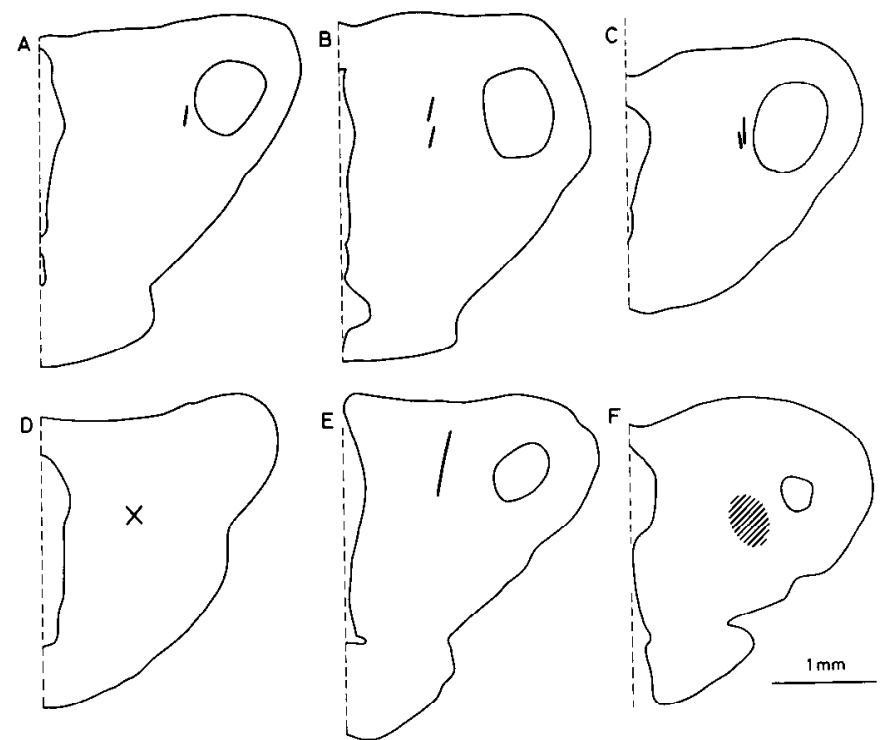

Figure 14. Histological localization of pretectal recording sites. $A, B, C$, and $E$ depict coronal sections $(35 \mu \mathrm{m})$ of the midbrain, where electrode tracks (dark lines) were located following recording from cells sensitive to horizontal optokinetic stimulation. $D$, Similar section showing the location of a few labeled fibers $(X)$ following HRP ejection from the recording microelectrode. $F$, Another pretectal injection site where reaction product was more dense (shaded area). In all instances cells were found in these regions activated by temporonasal optokinetic stimulation of the contralateral eye and activated at a short latency from electrical stimulation of the contralateral optic nerve. of the medulla at the level of the abducens nucleus (Fig. $16 E$ ) evoked a short-latency (Fig. $16 C$ ), all-or-nothing (Fig. 16D) action potential in this cell, which was found to collide with spontaneously occurring action potentials (Fig. 16B). Such short-latency antidromic potentials were found in 14 of 14 cells tested with medullary stimuli. The mean onset latency of extracellular antidromic spike potentials was $1.4 \pm 0.1 \mathrm{msec}$ (SEM: $n=14$; Fig. 15 , shaded bar). Successful replacement of the stimulating electrode more laterally or contralaterally failed to evoke such short-latency action potentials in these cells, but these spike potentials could still be evoked with the stimulating electrode located more caudally. In the case illustrated in Figure 16, the electrode was elevated above

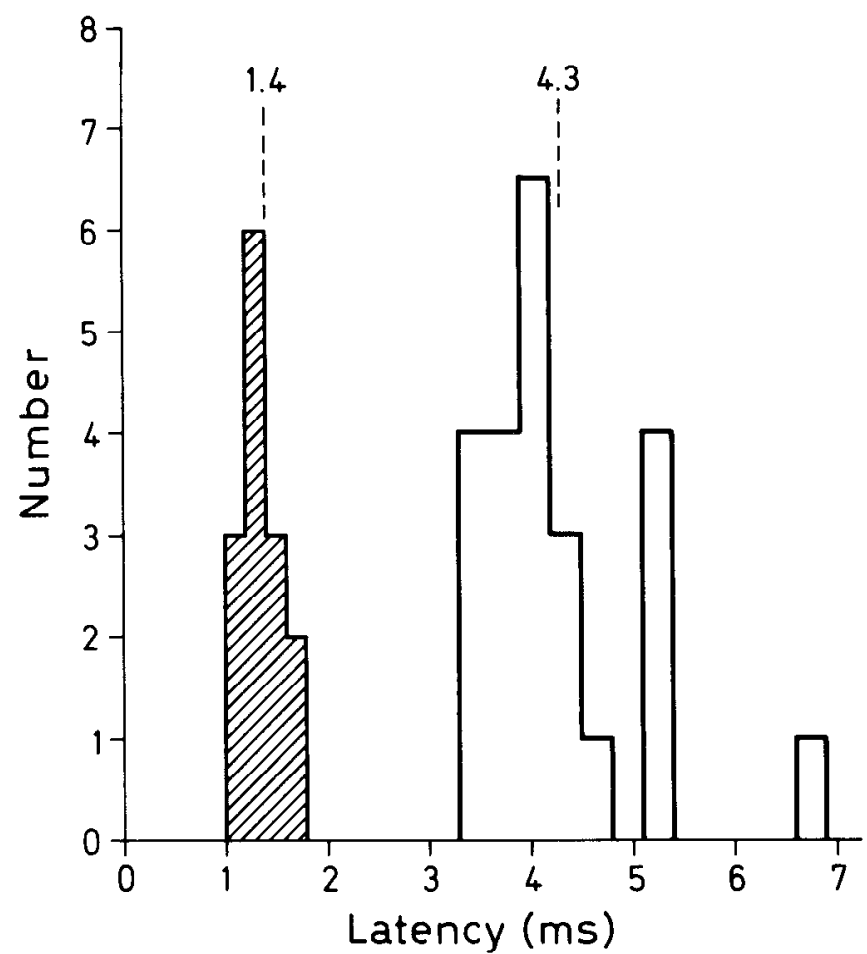

Figure 15. Histograms of response latencies of horizontal optokinetically sensitive pretectal neurons. Hatched columns, Extracellular spike onset latency in identified pretectal cells in response to electrical stimulation of the ipsilateral abducens nucleus. Open columns, Extracellular spike peak latencies in identified pretectal cells following contralateral optic nerve stimulation. Numbers above each histogram indicate mean latencies.

Figure 16. Activation of a horizontal optokinetically sensitive pretectal neuron $(A$ to $D)$ and localization of HRP reaction product following ejection from the recording microelectrode $(E$ to $I)$. $A$, Orthodromic activation from contralateral optic nerve stimulation (arrow, $C N I I$ ). Increasing the intensity of stimulation increased the size of the EPSP until the cell reached threshold. $B$ to $D$, Ipsilateral abducens nucleus stimulation (arrow, nuc VI) in $B$ did not evoke a short-latency action potential as in $C$, when a spontaneously occurring action potential preceded the stimulus. $D$, All-or-nothing response of this pretectal cell at threshold, indicating the lack of an underlying EPSP (ringing of the stimulus artifact is due to the limited frequency response of the tape recorder with which this cell's responses were recorded). E, Photomicrograph shows localization of stimulus electrode site at the level of the exit of the VIth cranial nerve $(n V I) . F$, Drawing of this coronal section $(70 \mu \mathrm{m})$. The larger box indicates the region included in $E$. The smaller box indicates the region of enlargement shown in $H$, where a few labeled axons can be seen (arrows). This labeling was the result of HRP ejection from the recording microelectrode (injection site drawn in $G$ and enclosed region enlarged as in $I$ ) following recordings obtained in $A$ to $D$. Calibration bars: $E, 100 \mu \mathrm{m} ; F, 0.5 \mathrm{~mm} ; G, 1 \mathrm{~mm} ; H, 50 \mu \mathrm{m} ; I$, $0.5 \mathrm{~mm}$. 
(A)
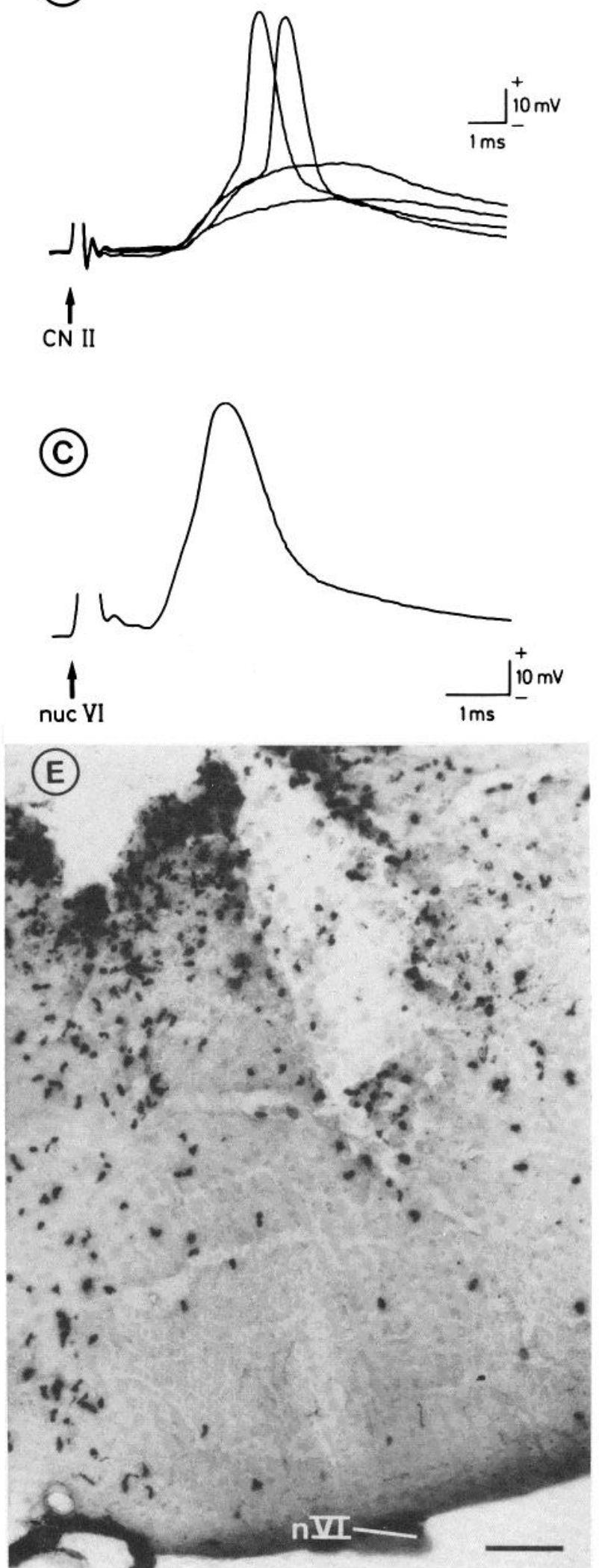

(B)

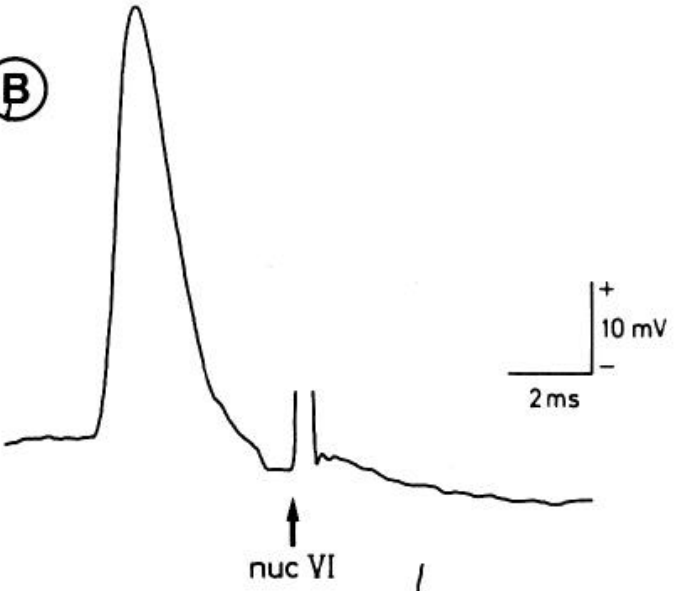

(D)

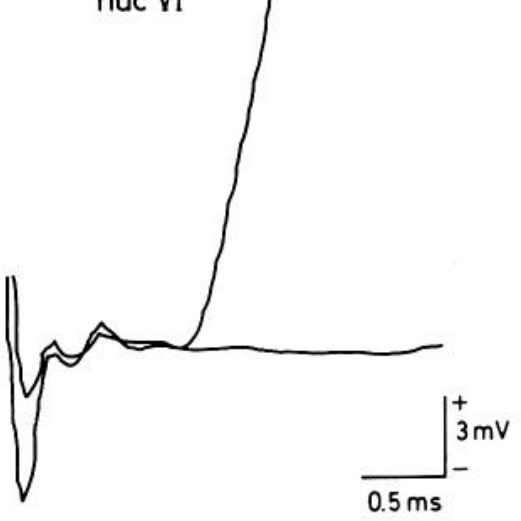

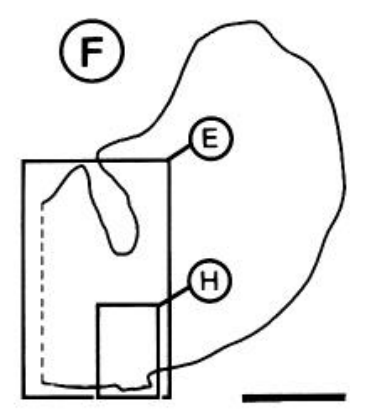
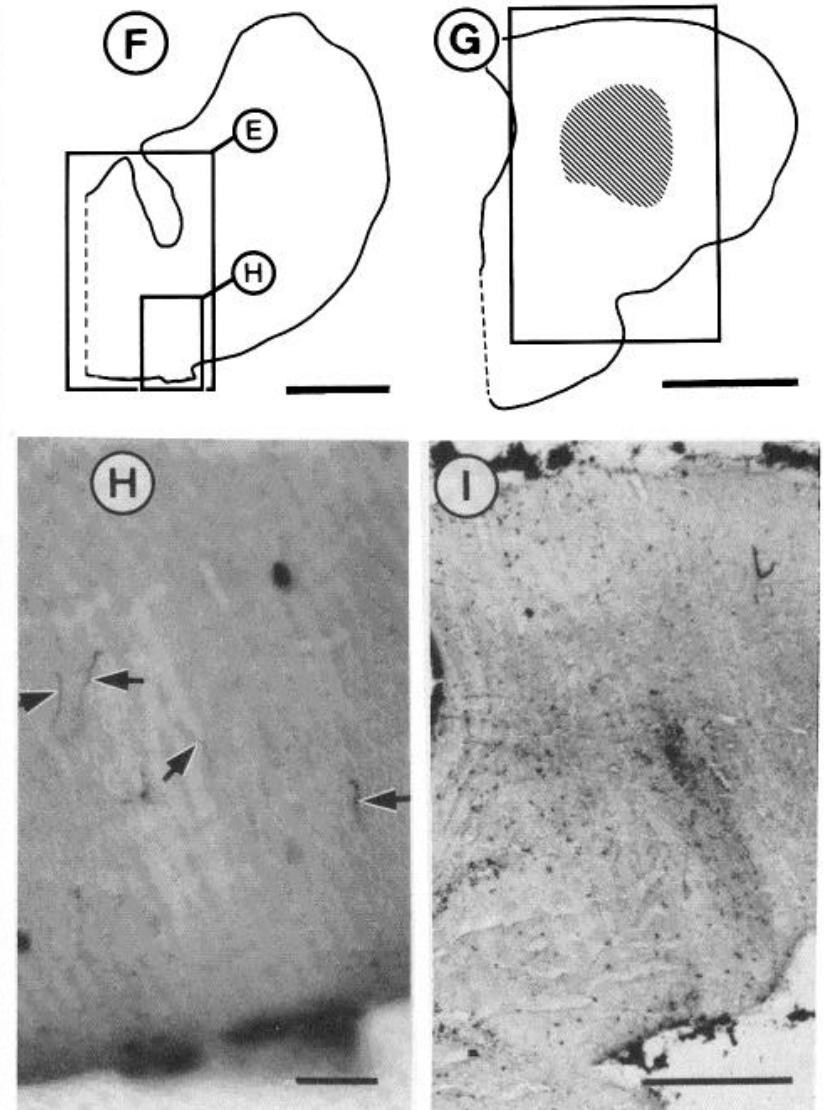

Figure 16 

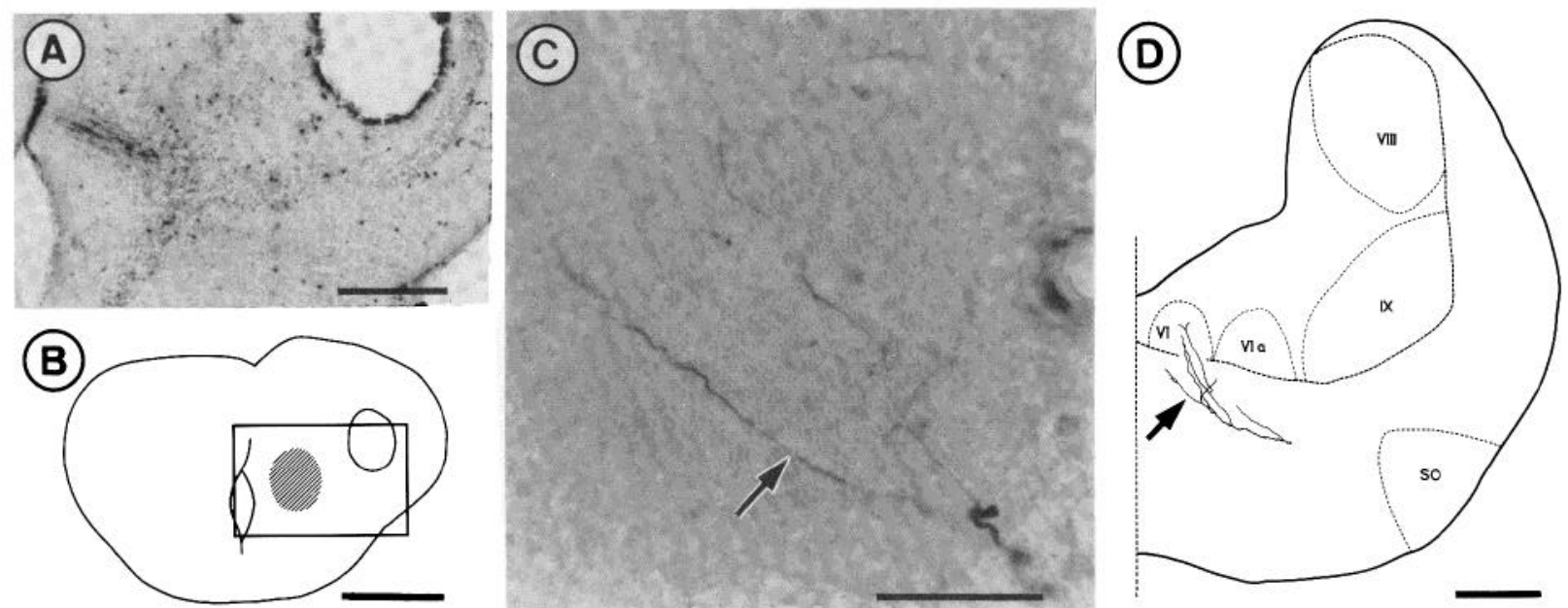

Figure 17. Labeling of axonal terminations in the abducens nucleus following HRP injection into the pretectum. $A$, Photomicrograph of injection site in pretectum drawn in $B$. $C$, Photomicrograph of axonal arborizations at the level of the abducens nucleus. $D$, Camera lucida reconstruction of the single afferent arborization into the region of the dendrites and somata of the abducens nucleus following this injection. This reconstruction is of $500 \mu \mathrm{m}$ of brain between the entrances of the VIIIth and IXth cranial nerves. The arrow indicates the axonal region shown in $C$. $V I$, abducens nucleus; VIa, accessory abducens nucleus; $V I I I$, vestibular nuclear complex; $I X$, vagal nucleus; $S O$, superior olive. Calibration bars: $A, 0.5 \mathrm{~mm} ; B, 1 \mathrm{~mm} ; C, 50 \mu \mathrm{m}$; $D, 0.25 \mathrm{~mm}$.

the brain, the tip broken from a resistance of approximately 100 megohms to approximately 10 megohms, and then reinserted to the same depth at which unitary recordings had been obtained. HRP was then electrophoretically injected (see injection site in Fig. 16, $G$ and $I$ ), and after histological processing, axons could be seen labeled with reaction product at the site of the stimulating electrode's position in the medulla, at the level of the abducens nucleus (Fig. 16, $E$ and $H$ ).

In four of five brains in which the pretectum was injected with HRP, axons could be followed into the medulla where they gave off collaterals in the region of the abducens nucleus and then continued caudally. Injection sites varied from 0.6 to $0.9 \mathrm{~mm}$ in diameter (Fig. $17 A$ ). Axons could be seen at this level to course ventrocaudally and then caudally in the ventromedial funiculus. At the level of the abducens nucleus (denoted by a region intermediate between the VIIIth and IXth cranial nerves, where often the stump of the exiting VIth cranial nerve remained intact), these axons collateralized and extended their arbors dorsally (Fig. 17, $C$ and $D$ ), while their main branch continued caudally to the level of the obex. Figure $17 D$ shows a drawing of such a collateralization of a single axon within the abducens nucleus proper.

In 10 of 13 frogs, when the abducens nucleus region was electrophoretically injected with HRP, cells were labeled in the pretectum, coincident with our recording site. Injection sites ranged from 0.3 to $1.2 \mathrm{~mm}$ in diameter and resulted in many cells being labeled, often including many reticular and vestibular nuclear complex cells, as well as midbrain cells. An example of such an injection is depicted in Figures 18 and 19. With cases of larger injections, more cells filled, and with smaller injections, fewer cells were labeled. More rostral and lateral injections, performed as controls (e.g., into the vestibular nuclear complex) did not result in pretectal labeling, although more caudal injections did.

\section{Discussion}

The sensory nuclei. Although, as stated in the introduction, the relatively small size of the frog brain as compared to that of the mammal facilitates its investigation, the poorly differentiated character of the frog brain is a hindrance. Nuclei are not well segregated as is often found to be the case in the mammal (see, for instance, Fig. 4). Midbrain regions have also been only marginally investigated and, in most instances, only anatomically in normal material (see Nieuwenhuys and Opdam, 1976). Associations of these anatomically defined regions on the grounds of homology or physiology are either lacking or tenuous. It is thus with a great deal of caution that we have adopted the nuclear boundaries defined by Niewenhuys and Opdam (1976) and Neary and Wilczynski (1977) in Figures $17 D$ and 19. Further investigations may reveal, as suggested by Ebbesson (1976) in the spinal cord, that related neuronal populations in the frog are better defined by the terminal neuropils their dendrites invade, rather than on a purely cytoarchitectural basis. The findings of Montgomery et al. (1981) upon the basal optic nucleus bear out this conclusion. The basal optic nucleus is actually a conglomeration of seven types of cells that are to various extents separated from each other anatomically, but all of which send their dendrites into the terminal neuropil of the basal optic root (see Montgomery et al., 1981, Fig. 8 ). This diffuse anatomical organization of frog nuclei is in contrast to the apparently well segregated nuclei reported in the mammal and has greatly hindered our experimentation and its interpretation, particularly with regard to anatomical localization of the pretectal nucleus. These difficulties have necessitated the combination of anatomy with electrophysiology in this study so that multiple, conjoint definitions of these cell populations are possible, leading to less equivocal recognition. 

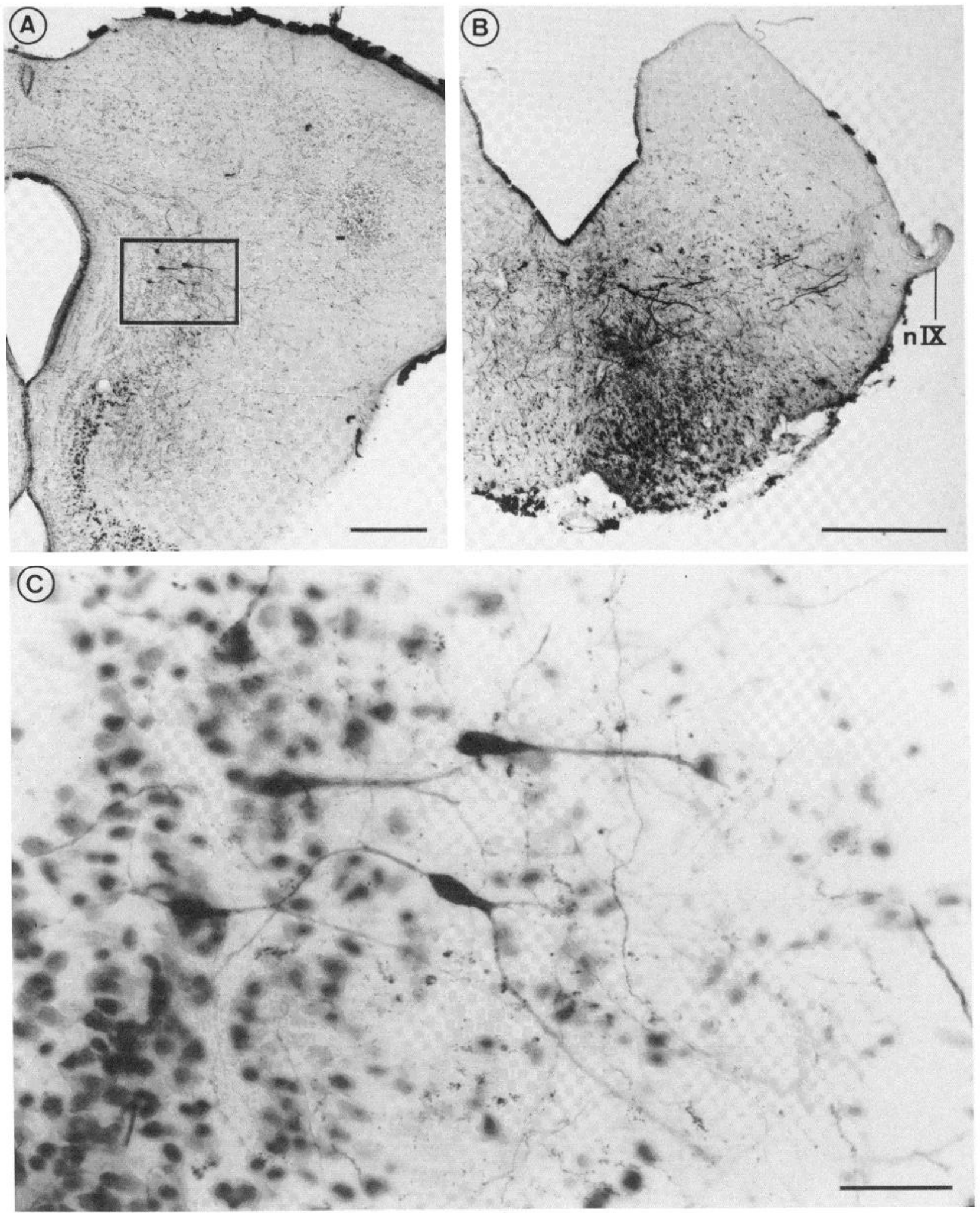

Figure 18. Labeling of pretectal neurons following HRP injection into the abducens nucleus. $A$, Photomicrograph of the pretectal region (drawn in Fig. 19B) showing perikaryal labeling. The boxed region is enlarged in $C$. $B$, Photomicrograph of injection site. The abducens nerve was detached from these sections due to damage. However, the presence of the rostral portion of the IXth cranial nerve $(n I X)$ indicates the injection was in the region of the abducens nucleus. Calibration bars: $A, 0.25$ mm; $B, 0.5 \mathrm{~mm} ; C, 50 \mu \mathrm{m}$. 
A
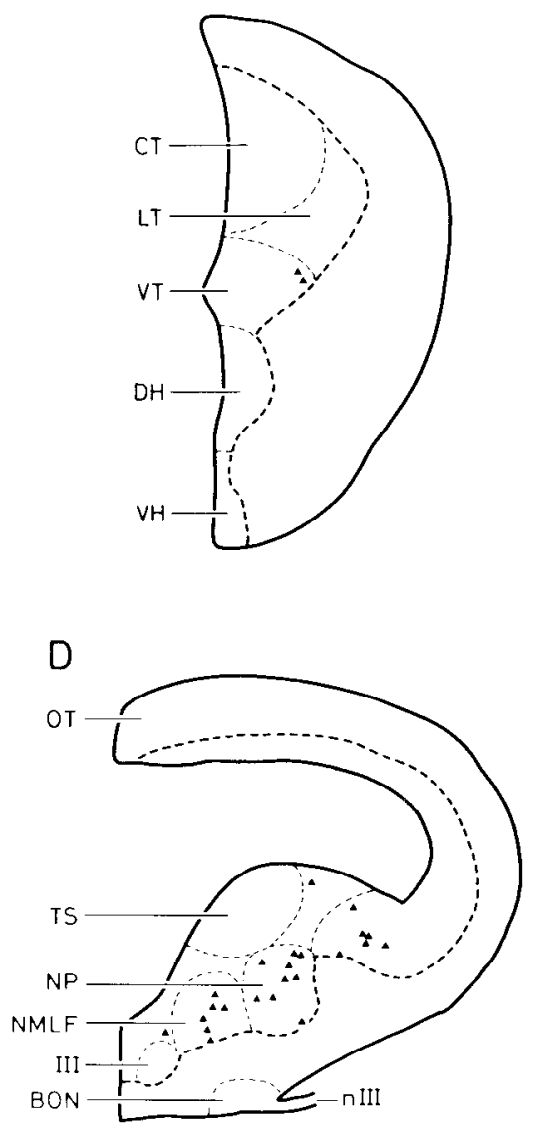

B
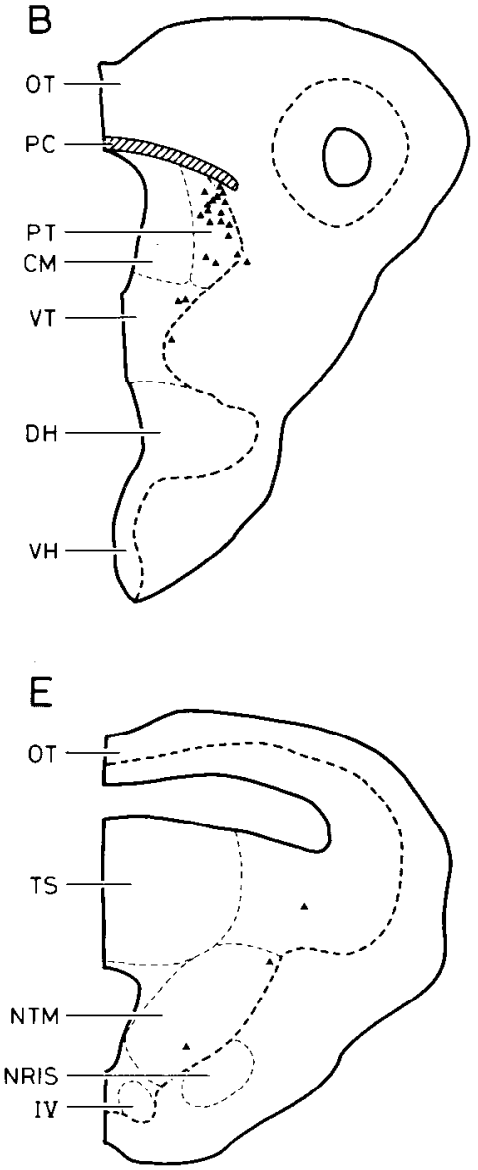

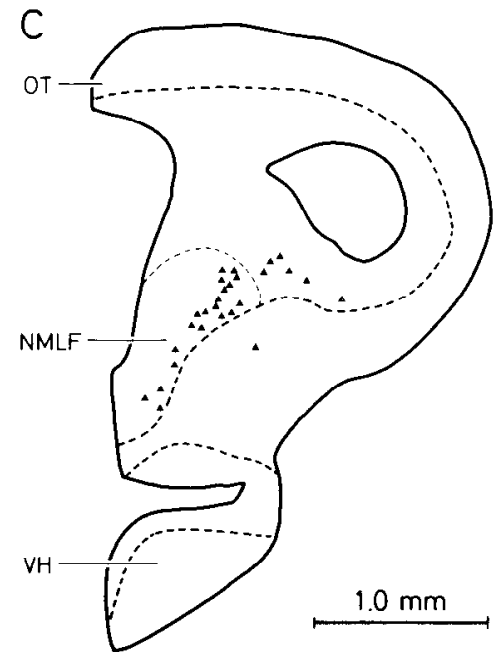

III Oculomotor Nucleus IV Trochlear Nucleus BON Basal Optic Nucleus CT Central Thalamic Nucleus $\mathrm{OH}$ Dorsal Hypothalamic Nucleus LT Lateral Thalamic Nucleus $n$ III Oculomotor Nerve NMLF Nucleus Medial Longitudinal Fasciculus NP Nucleus Profundus NRIS Nucleus Reticularis Isthmi NTM Nucleus Tegmenti Mesencephali

OT Optic Tectum PC Posterior Commissure PT Pretectal Nucleus

IS Torus Semicircularis VH Ventral Hypothalamic Nucleus $\checkmark T$ Ventral Thalamic Nucleus

Figure 19. Distribution of ipsilateral labeled perikarya (triangles) in one frog (Fig. 18) following HRP injection into the abducens nucleus (Fig. 18B). PT (in $B$ ) represents the region were horizontal optokinetically sensitive cells are found (approximately $1 \mathrm{~mm}$ ventral to the rostral tectal surface). Nuclear regions are delineated as per Nieuwenhuys and Opdam (1976) and Neary and Wilczynski (1977). Each coronal section represents a thickness of $350 \mu \mathrm{m}$.

Bearing these difficulties in mind, it is still clear that two discrete midbrain nuclei receive direct retinal inputs which communicate optokinetic signals. This conclusion was suggested by the work of Katte and Hoffman (1980), who found units in the pretectal region predominantly sensitive to horizontal optokinetic stimulation and other units, closer to the basal optic region, predominantly sensitive to vertical optokinetic stimulation. Our findings concur with theirs and, in addition, demonstrate that in these two regions there are perikarya which are excited by contralateral retinal afferents and which respond to optokinetic stimulation. That these cells receive a monosynaptic input is corroborated by the short latency of the EPSPs in these cells (similar to those found in the optic tectum (Matsumato and Bando, 1980)), by the relatively fixed latency of the EPSPs evoked from contralateral optic nerve stimulation (Figs. 8, B1 and B2, and $16 \mathrm{~A}$ ), and by anatomical data, which confirm that these regions are innervated by the contralateral retina (Scalia, 1976; Montgomery et al., 1981).

These sensory nuclei are similar in many respects. They are both located at the midbrain border between the diencephalon and mesencephalon, they both receive a direct input from the contralateral retina, and they both are sensitive to optokinetic pattern movement. However, these nuclei differ in their preferred directions, and possibly in their optimal velocities, and receptive field sizes. Basal optic neurons prefer vertical and nasotemporally directed movements and seem to be optimally sensitive to very slow pattern movements, and they require nearly full-field patterns to activate the cells. Pretectal neurons, however, prefer horizontal movements (being activated by temporonasal patterns moved in front of the contralateral eye), are apparently optimally sensitive to faster pattern movements ( 5 to $10^{\circ} / \mathrm{sec}$ ), and can be activated by patterns which need not involve the whole visual field.

These nuclei are similar in many respects to nuclei found in other vertebrates (see Mai, 1978, for review). Not only is the frog basal optic nucleus located in a position identical to that found for the ectomamillary nucleus in birds (Brecha and Karten, 1979) and the lateral and medial terminal nuclei of the rabbit (Simpson ct al., 1979) (ventrolateral and slightly rostral to the oculomotor complex), but this nucleus is also functionally similar. Cells of the frog basal optic nucleus, the bird ectomamillary nucleus, and the rabbit medial and lateral terminal nuclei are all innervated by retinal ganglion cells from the contralateral eye, and all respond selectively to large optokinetic targets, moved vertically at very slow velocities (see also Manteuffel (1982) in the newt). In contrast to findings in other vertebrates (Simp- 
son et al., 1979; Burns and Wallman, 1981; Morgan and Frost, 1981), in our studies basal optic neurons were for the most part spontaneously inactive. Thus, in most instances we were unable to determine preferred and null directions of stimulation, which in other vertebrates are often not $180^{\circ}$ apart. As we have found in the frog, some cells in the bird and rabbit nuclei possess a sensitivity to nasotemporally moved targets, but little, if any, activation to patterns moved horizontally in the temporonasal direction.

Although few studies have investigated a similar region in birds (Gioanni et al., 1980, 1983; McKenna and Wallman, 1980), the region of the horizontally sensitive pretectal cells in the frog is quite similar both in its location and in its visual sensitivity to the nucleus of the optic tract and dorsal terminal nuclei (which may be contiguous) of rabbits (Collewijn, 1975a, b; Simpson et al., 1979), rats (Cazin et al., 1980), and cats (Hoffman and Schoppman, 1975). In all of these vertebrates, the cells of these nuclei are innervated by contralateral retinal ganglion cells, are sensitive to temporonasally moved stimuli at comparable velocities, and do not require extremely large receptive fields (as do the vertically sensitive neurons). Again, as we have not investigated all angles of movement, we cannot exactly define the preferred and null directions of these cells, but, in agreement with Katte and Hoffman (1980), it is clear that temporonasally moved stimuli greatly increase the firing rates of these cells, whereas nasotemporally moved stimuli reduce their spontaneous activity often to zero. In a wide spectrum of vertebrates studied, there is, then, a remarkable similarity in these primary visual relay centers of optokinetic information.

Our findings would then suggest that in the frog, as well as in other vertebrates, these two relay centers, the basal optic and the pretectal nuclei, are responsible for signaling vertical and horizontal optokinetic pattern movement, respectively. Lesion studies in the frog (Cochran et al., 1980; Fite and Montgomery, 1982; Montgomery et al., 1982), in birds (Fite et al., 1979; Wallman et al., 1981; Gioanni et al., 1983), and in mammals (Collewijn, 1975b) further indicate that the integrity of these nuclei is essential for the mediation of the optokinetic behavior. These studies are in contradiction to the conclusion of Lázár (1973) that, in the frog, the basal optic nucleus is responsible for mediating the horizontal optokinetic responsiveness of the animal. This discrepancy may be explained by the relatively extensive nature of Lázár's lesions, which may not have involved the basal optic nucleus or the accessory optic system exclusively. All other studies, in a wide variety of vertebrates, support the conclusion that the basal optic nucleus is predominantly involved with vertical optokinetic sensitivity and the pretectal region is predominantly involved with horizontal optokinetic sensitivity.

Extraocular motoneurons. The functional distinctions between individual types of basal optic neurons and between the basal optic and pretectal nuclei are maintained in the cell types found in the extraocular motor nuclei. That is, the four different types of vertical direction specificity found in the basal optic neurons are also found in the extraocular motoneurons, and the one pre- dominantly horizontal specificity is found in both the pretectum and the extraocular motoneurons (pretectal neurons contralateral, oculomotor neurons ipsilateral, and abducens motoneurons contralateral to the seeing eye). The preferred velocities and receptive field sizes necessary to provoke responses from these cell types are also similar between the sensory and motor nuclei, although further studies that quantitate these parameters are necessary.

It is tempting to assign these five cell types to the six eye muscles innervated by these nuclei. Thus horizontally sensitive abducens and oculomotor neurons would feasibly innervate the lateral and medial recti, respectively, while the superior oblique would receive input from the up/nasotemporally sensitive motoneurons, the inferior rectus from down/nasotemporally sensitive motoneurons, and the superior rectus and inferior oblique from the exclusively up and down sensitive motoneurons, respectively. However, because the muscular innervation and control of the frog's eye movements is poorly understood, it is conceivable that, instead of these individual cell types (particularly those vertically sensitive) innervating individual muscles, they rather innervate different motor units of the same and different muscles. In addition, the receptive field characteristics of these cells may have been deceptively oversimplified as we have studied only two directions of movement. Instead, intermediate movement directions may be preferred by some of these cells, as is found in the rabbit (Simpson et al., 1979). An assessment of these possibilities is beyond the scope of this study.

Do the primary sensory centers innervate the extraocular motoneurons? Our findings suggest, particularly with regard to the pretectal-abducens projection, that the axons of the optokinetic sensory nuclei directly innervate the extraocular motoneurons. However, definitive proof of such a hypothesis does not exist. The short-latency EPSPs found in the extraocular motoneurons, consequent from optic nerve stimulation, do not of necessity have to arise from optokinetically sensitive neurons. Other cells, such as those in the tectum, may also have their own contribution to the disynaptic EPSPs, especially since, although not found in the case illustrated in Figures 18 and 19, tectal cells were often labeled following HRP injection into the abducens region. Similarly, stimulation of the abducens nucleus could obviously not be selective, in that, most likely, many axons were activated, and it just may be by chance that the axons of the horizontal optokinetically sensitive pretectal neurons passed near enough to the abducens nucleus to be also activated. Although we could in part localize these axons by moving the stimulating electrode laterally and no longer obtain antidromic responses, and although many other pretectal cells not sensitive to optokinetic stimulation were not activated at a short latency by these electrical stimuli, we cannot claim that the stimulating electrode only activated axons which synapsed with horizontally sensitive abducens motoneurons. Similarly, HRP injections, although we have in part controlled for diffusion to other regions by varying sites of injection, could have stained (and no doubt did stain) other axons, which, rather than projecting to abducens, merely were 
in its vicinity. Furthermore, pretectal injections also could not be restricted to those cells, which are sensitive to horizontal optokinetic stimulation and which are innervated by the retina, but rather may also have involved other neighboring axons, which may have synapses upon abducens motoneurons.

Thus, our results cannot definitively prove that the horizontal optokinetically sensitive pretectal sensory neurons synapse directly with the horizontal optokinetically sensitive motoneurons. However, the optokinetic sensitivities of these two populations are quite similar; abducens motoneurons do receive a disynaptic input from the retina; horizontally sensitive pretectal neurons can be activated antidromically from abducens stimulation; these pretectal cells, or cells in this vicinity are labeled following HRP injection into the abducens; and afferent terminals are found in the midst of the abducens nucleus following pretectal injection $(1 \mathrm{~mm}$ ventral to the rostral tectal surface at the level of the posterior commissure; Fig. $17 \mathrm{C}$ ). Thus there is strong support for the hypothesis of such a three-neuronal connection from retina to motoneuron.

Little is known as to whether such direct retino-ocular pathways may also exist in other vertebrates. Our findings support those of Montgomery et al. (1981) who found, using Golgi, autoradiographic, and HRP analyses, that the basal optic nucleus projects to the oculomotor nucleus. Such projections from the basal optic (ectomamillary) nucleus to the oculomotor and trochlear nuclei in the pigeon have been reported and confirmed (Brecha and Karten, 1979; Britto et al., 1981). In mammals, however, such projections have not been reported. A pretectal region in the tree shrew has been demonstrated to project to the oculomotor nucleus (Weber and Harting, 1980 ), but it is not clear that this projection conveys optokinetic information and arises from cells innervated by the retina. Similarly, Holstege and Collewijn (1981), studying the rabbit, have shown a projection from the nucleus of the optic tract to the region of the abducens, but not to the oculomotor (see Collewijn, 1981, p. 934), nucleus. Almost nothing is known about primary optokinetic centers in primates. Thus it remains to be determined whether these direct connections are present to various extents in various vertebrates, or whether frogs and a few other vertebrates are somewhat unique in this regard.

These three neuronal reflexes could enact the initiation of eye movement during an optokinetic stimulus. In order to attain steady gaze, the eye must accelerate from rest to a velocity matching that of the stimulus. Passing the sensory retinal slip velocity signal directly from the midbrain to the motoneuron would result in a strong muscular contraction that overcomes the initial inertia of the eye at rest (as suggested by Rurns and Wallman, 1981) and accelerates the eye toward its final velocity. This velocity is reached in the frog within 1 sec of stimulation (Dieringer and Precht, 1982). As this velocity is achieved, retinal slip is decreased, the activity of this pathway is thereupon diminished, and the influence of more indirect pathways, such as those mediating "central integration" (Robinson, 1977), becomes dominant in acting to guide and hold the eye in position (Dieringer and
Precht, 1983). These three-neuronal pathways, then, may be considered to accelerate the eye following the onset of optokinetic stimulation and following transient velocity changes, but may be less important during the subsequent operations of gaze-stabilizing reflexes such as holding the eye in position. Such an interpretation, however, must be considered simplistic until more is known about the neuronal populations that govern the frog's optomotor behavior.

\section{References}

Birukow, G. (1937) Untersuchungen über den optischen Drehnystagmus und über die Sehschärfe des Grasfrosches (Rana temporaria). Z. Vgl. Physiol. 25: 92-142.

Brecha, N., and H. J. Karten (1979) Accessory optic projections upon oculomotor nuclei and vestibulocerebellum. Science 203: 913-916.

Britto, L. R. G., C. L. Natal, and A. M. Marcondes (1981) The accessory optic system in pigeons: Receptive field properties of identified neurons. Brain Res. 206: 149-154.

Brown, K. T., and D. G. Flaming (1974) Beveling of fine micropipette electrodes by a rapid precision method. Science 185: 693-695.

Burns, S., and J. Wallman (1981) Relation of single unit properties to the oculomotor function of the nucleus of the basal optic root (accessory optic system) in chickens. Exp. Brain Res. 42: 171-180.

Cazin, L., W. Precht, and J. Lannou (1980) Firing characteristics of neurons mediating optokinetic responses of vestibular nucleus neurons in the rat. Pflüger's Arch. 386: 221230.

Cochran, S. L., and W. Precht (1980) Electrophysiological characterization of the basal optic region in the anuran. Proc. Int. Union Physiol. Sci. 14: 1100.

Cochran, S. L., W. Precht, and N. Dieringer (1980) Directionselective neurons in the frog's visual system. Soc. Neurosci. Abstr. 6: 839 .

Cochran, S. L., W. Precht, and N. Dieringer (1981a) Neuronal mediation of optokinetic reflexes in the frog. Experientia (Suppl.) 37: 6.

Cochran, S. L., W. Precht, and N. Dieringer (1981b) Responses of sensory relay neurons and extraocular motoneurons to optokinetic stimulation in the frog. Soc. Neurnsci. Abstr. 7: 23.

Collewijn, H. (1975a) Direction-selective units in the rabbit's nucleus of the optic tract. Brain Res. 100: 489-508.

Collewijn, H. (1975b) Oculomotor areas in the rabbit's midbrain and pretectum. J. Neurobiol. 6: 3-22.

Collewijn, H. (1981) Studies of Brain Functions: The Oculomotor System of the Rabbit and Its Plasticity. SpringerVerlag, Berlin.

Dieringer, N., and W. Precht (1982) Compensatory head and eye movements in the frog and their contribution to stabilization of Gaze. Exp. Brain Res. 47: 394-406.

Dieringer, N., and W. Precht (1983) Functional specialization in the final "common" pathway of the ocular motor system of frogs. Neurosci. Lett. (Suppl.) 14: 92.

Dieringer, N., W. Precht, and A. R. Blight (1982a) Resetting fast phases of head and eye and their linkage in the frog. Exp. Brain Res. 47: 407-416.

Dieringer, N., W. Precht, and S. L. Cochran (1982b) Is there a velocity storage in the frog brain stem? Neurosci. Lett. (Suppl.) 10: 145 .

Ebbesson, S. O. E. (1976) Morphology of the spinal cord. In Frog Neurobiology, R. Llinás and W. Precht, eds., pp. 679706, Springer-Verlag, Berlin.

Fite, K. V., and N. Montgomery (1982) Neuronal correlates of 
optokinetic nystagmus (OKN) in the amphibian mesencephalon: A functional analysis. Neuroscience (Suppl.) 7: 69 .

Fite, K. V., A. Reiner, and S. P. Hunt (1979) Optokinetic nystagmus and the accessory optic system of pigeon and turtle. Brain Behav. Evol. 16: 192-202.

Gaupp, E. (1896) Anatomie des Frosches. Vieweg und Sohn, Braunschweig, Germany.

Gioanni, H., J. Rey, and J. Villalobos (1980) Étude du nystagmus optocinétique horizontal chez le pigeon: Rôle du système optique accessoire. C. R. Acad. Sci. Paris 291: 909-912.

Gioanni, H., J. Rey, J. Villalobos, D. Richard, and A. Dalbera (1983) Optokinetic nystagmus in the pigeon (Columba livia). II. Role of the pretectal nucleus of the accessory optic system. Exp. Brain Res. 50: 237247.

Graham, R. C., and M. J. Karnovsky (1966) The early stages of absorption of injected horseradish peroxidase in the proximal tubes of mouse kidney: Ultrastructural cytochemistry by a new technique. J. Histochem. Cytochem 14: 291-302.

Gruberg, E. R., and K. L. Grasse (1980) Basal optic projection in the frog (Rana pipiens). Soc. Neurosci. Abstr. 6: 121.

Hoffman, K. P., and A. Schoppman (1975) Retinal input to direction selective cells in the nucleus tractus opticus of the cat. Brain Res. 99: 359-366.

Holstege, G., and H. Collewijn (1982) The efferent connections of the nucleus of the optic tract and the superior colliculus of the rabbit. J. Comp. Neurol. 209: 139-178.

Katte, O., and K. P. Hoffman (1980) Direction specific neurons in the pretectum of the frog. (Rana esculenta). J. Comp. Physiol. 140: 53-57.

Kondrashev, S. I., and O. Ju. Orlov (1976) Role of accessory visual system in evoking optokinetic reactions in anuran amphibians. Sci. Reports of High School USSR, Ser. Biol. Sci. $n l: 68-74$.

Iázár, G. (1973) Role of the accessory optic system in the optokinetic nystagmus of the frog. Brain Behav. Evol. 5: 443460.

Mai, J. K. (1978) The accessory optic system and retinohypothalamic system. A review. J. Hirnforsch. 19: 213-288.

Manteuffel, G. (1982) The accessory optic system in the newt, Triturus cristatus: Unitary response properties from the basal optic neuropil. Brain Behav. Evol. 21: 175-184.

Matesz, C., and G. Székely (1977) The dorsomedial nuclear group of cranial nerves in the frog. Acta Biol. Acad. Sci. Hung. 28: 461-474.

Matsumato, N., and T. Bando (1980) Excitatory synaptic potentials and morphological classification of tectal neurons of the frog. Brain Res. 192: 39-48.

McKenna, O., and J. Wallman (1980) Metabolic mapping of avian brain areas responsive to retinal slip. Soc. Neurosci. Abstr. 6: 840 .
Montgomery, N., K. V. Fite, and L. Bengstrom (1981) The accessory optic system of Rana pipiens: Neuroanatomical connections and intrinsic organization. J. Comp. Neurol. 203: 595-612.

Montgomery, N., K. V. Fite, M. Taylor, and L. Bengston (1982) Neural correlates of optokinetic nystagmus in the mesencephalon of Rana pipiens: A functional analysis. Brain $\mathrm{Be}-$ hav. Evol, 21: 137-150.

Morgan, B., and B. J. Frost (1981) Visual response character istics of neurons in nucleus of basal optic root of pigeons. Exp. Brain Res. 42: 181-188.

Neary, T. J., and W. Wilczynski (1977) Ascending thalamic projections from the obex region in ranid frogs. Brain Res. 138: 529-533.

Nieuwenhuys, R., and P. Opdam (1976) Structure of the brain stem. In Frog Neurobiology, R. Llinás and W. Precht, eds., pp. 811-855, Springer-Verlag, Berlin.

Precht, W. (1982) Anatomical and functional organization of optokinetic pathways. In Functional Basis of Ocular Motility Disorders, G. Lennerstrand, P. Bach-y-Rita, C. C. Collins, A. Jampolski, and A. B. Scott, eds., pp. 219-302, Pergamon Press, Oxford.

Robinson, D. A. (1977) Vestibular and optokinetic symbiosis: An example of explaining by modelling. In Control of Gaze by Brain Stem Neurons, R. Baker and A. Berthoz, eds., pp. 49-58, Elsevier/North-Holland Biomedical Press, Amsterdam.

Scalia, F. (1976) The optic pathway of the frog: Nuclear organization and connections. In Frog Neurobiology, R. Ilinás and W. Precht, eds., pp. 386-406, Springer-Verlag, Berlin.

Simpson, J. I., R. E. Soodak, and R. Hess (1979) The accessory optic system and its relation to the vestibulocerebellum. Prog Brain Res. 50: 715-724.

Skarf, B., and G. Melvill--Jones (1981) Vestibular-visual interactions in frog mesencephalon during natural stimulation. Brain Res. 206: 457-461.

Snow, P. J., P. K. Rose, and A. G. Brown (1976) Tracing axons and axon collaterals of spinal neurons using intracellular injection of horseradish peroxidase. Science 191: 312-313.

Wallman, J., J. Velez, and O. C. McKenna (1981) Lesions of avian accessory optic system severely disrupt optokinetic nystagmus in non-horizontal directions. Soc. Neurosci. Abstr. 7: 299.

Weber, J. T., and J. K. Harting (1980) The efferent projections of the pretectal complex: An autoradiographic and HRP analysis. Brain Res. 194: 1-28.

Williams, B., J. Amat, and II. Vanegas (1981) Visual, vestibular, and proprioreceptive input to the mesencephalic nucleus isthmi (NI) in teleosts and amphibians. Neurosci. Lett. (Suppl.) 7: 110. 